\title{
Asymmetric Volatility Risk: Evidence from Option Markets*
}

\author{
Jens Jackwerth
}

\author{
Grigory Vilkov
}

This version: September 10, 2015

\begin{abstract}
We show how to extract the expected risk-neutral correlation between risk-neutral distributions of the market index (S\&P 500) return and its expected volatility (VIX). Comparing the implied correlation with its realized counterpart reveals a significant index-to-volatility correlation risk premium. It compensates for the fear of enduring negative market returns and measures a new dimension of conditional risk not covered by other variables such as the variance risk premium or skewness. Incorporating information from both equity and volatility markets, it predicts future investment opportunities and (conditional as well as unconditional) risk.
\end{abstract}

Keywords: Asymmetric volatility, SPX options, VIX options, implied correlation, leverage effect

JEL: G11, G12, G13, G17

\footnotetext{
* Corresponding author: Jens Jackwerth is from the University of Konstanz, PO Box 134, 78457 Konstanz, Germany, Tel.: +49-(0)7531-88-2196, Fax: +49-(0)7531-88-3120, jens.jackwerth@uni-konstanz.de;

Grigory Vilkov is from the Frankfurt School of Finance \& Management, Germany, vilkov@vilkov.net.

We received helpful comments and suggestions from Raman Uppal, Bjorn Eraker, Axel Kind, Turan Bali, Guenter Franke, Nikunj Kapadia, Pascal Létourneau, Paulo Rodrigues, Loriana Pelizzon, and Paul Schneider. We thank participants of the Western Finance Association 2015 Meeting, IFSID Third Conference on Derivatives in Montreal, ESSFM 2013 Seminar at Gerzensee, and seminar participants at the Frankfurt School of Finance \& Management, Goethe University of Frankfurt, University of Lugano, University of Manchester, University of Mannheim, the Swiss Finance Institute at EPFL, Tinbergen Institute/Duisenburg School of Finance, 2013 OptionMetrics Research Conference, University of Konstanz, EDHEC, University of South Australia, and University of Zurich.
} 


\title{
Asymmetric Volatility Risk: Evidence from Option Markets
}

This version: September 10, 2015

\begin{abstract}
We show how to extract the expected risk-neutral correlation between risk-neutral distributions of the market index (S\&P 500) return and its expected volatility (VIX). Comparing the implied correlation with its realized counterpart reveals a significant index-to-volatility correlation risk premium. It compensates for the fear of enduring negative market returns and measures a new dimension of conditional risk not covered by other variables such as the variance risk premium or skewness. Incorporating information from both equity and volatility markets, it predicts future investment opportunities and (conditional as well as unconditional) risk.
\end{abstract}

Keywords: Asymmetric volatility, SPX options, VIX options, implied correlation, leverage effect

JEL: G11, G12, G13, G17 


\section{Introduction}

Asymmetric volatility risk is one of the fundamental drivers of asset prices in that the correlation between returns and expected future volatility ${ }^{1}$ determines how future volatility is expected to react to moves in returns. The average realized correlation of -0.75 indicates severe concerns of market participants about poor (good) returns which translate into elevated (subdued) levels of expected future volatility. The empirical standard deviation of 0.07 suggests that this risk perception is time-varying. Unlike the expected moments of the marginal return distribution (e.g., the volatility or skewness of market returns), index-to-volatility implied correlation reflects conditional risk, i.e., it measures uncertainty about how distant future investment opportunities are expected to react to short-term market returns.

Our goal is to understand which role asymmetric volatility risk plays in asset pricing. In particular, we find a suitable measure for asymmetric volatility risk (implied index-to-volatility correlation), shows that this risk is priced, and we offer a hedging trading strategy that pays off when there is a pronounced realized asymmetric volatility (i.e., more negative realized indexto-volatility correlation). We demonstrate that expectation of a stronger asymmetric volatility leads not to more negatively skewed future returns (as might be expected) but to more positively skewed future returns, while at the same time the left tail of the future return distribution grows fatter.

Note that implied correlation should not be interpreted as a fear gauge like the VIX. It is about how volatility unfolds (arriving unconditionally or conditionally on a negative return) and not about at what level (high or low). So while VIX tells us to expect much or little volatility, implied correlation tells us if the volatility will arrive independent of the first-period return (implied correlation close to zero) or hit the investor strongly after a negative return while sparing one after a positive return (implied correlation close to -1). Economically, the second situation is much worse as one gets kicked when down on the floor-thus the need for a risk premium to compensate and a stronger (or longer) price adjustment in the later period. One consequence is the ability of implied correlation to predict lower second period returns conditional on a negative first period return.

\footnotetext{
${ }^{1}$ Actually, we always use changes in expectations of future volatility, but we abbreviate the wording to "expected future volatility."
} 
We start with the realized correlation between return and future expected volatility. Next, we work out the risk-neutral version of that same index-to-volatility correlation from options on the S\&P 500 and on VIX. We present a novel method for finding the risk-neutral bivariate distribution from option prices on the index and expected volatility. Because there are no basket options written on both the market index and its volatility simultaneously, this feat is deemed impossible in the literature. But we use information from longer dated index options to achieve just that. We compute the implied correlation risk premium, defined as the risk-neutral correlation minus the realized correlation, and analyze its properties.

We contribute to the literature in two ways, namely, in stylized and empirical settings.

\subsection{Mechanics of implied correlation and the asymmetric volatility effect}

We start out by showing a simple bivariate tree in Figure 1 with a marginal return distribution of equally probable up and down moves and a marginal volatility distribution of a low volatility state $\left(\sigma^{l}=0.2\right)$ with probability 0.6 and a high volatility state $\left(\sigma^{h}=0.6\right)$ with probability 0.4. For ease of exposition, we assume in Panel A that the two marginal distributions are uncorrelated. As a result, at time 1, we are faced with four different states (depicted in white boxes): a high stock price and high volatility (probability of 0.2 ), a high stock price and low volatility (0.3), a low stock price and high volatility $(0.2)$, and finally a low stock price and low volatility (0.3). Assuming that the up and down move probabilities remain at 0.5 for the second period, we can derive the two-period distribution of stock prices.

In panel $\mathrm{B}$, we change the correlation to -0.41 , changing the four joint probabilities of reaching the four particular combinations of stock price and expected volatility at time 1 (compare the probabilities in the white and yellow boxes across panels) and hence also the two-period distribution. As implied correlation becomes more negative (moving from 0 to -0.41), the conditional volatility after a negative return goes up from $\frac{0.2}{0.5} \cdot 0.6+\frac{0.3}{0.5} \cdot 0.2=0.36$ to $\frac{0.3}{0.5} \cdot 0.6+\frac{0.2}{0.5} \cdot 0.2=0.44$, as befits asymmetric volatility. ${ }^{2}$

Closely related, the left tail of the two-period distribution of the market becomes fatter, with a probability of 0.15 of ending at the lowest stock price of 0.2 in the asymmetric volatility

\footnotetext{
${ }^{2}$ We have a 0.2 probability of high volatility out of a total probability of 0.5 of being at the low stock price times a volatility of 0.6 plus 0.3 out of 0.5 of having a volatility of 0.2 , and similarly for 0.44
} 
Figure 1: Illustration 1

The figure shows an example of a stock process over two periods, where the initial stock price of 1 can move to $S^{u}=1.2$ or to $S^{d}=0.8$. The probability of an up-move from a given state is always 0.5 . The stock return volatility at $t=1$ can either be high $\left(\sigma^{h}=0.6\right.$, red lines), or low ( $\sigma^{l}=0.2$, blue dotted lines). In Model 1 (Panel A) are the joint probability of being at $t=1$ in the up state with high expected probability $\left(S^{u}, \sigma^{h}\right) 0.2$ and in the up state with low expected volatility $\left(S^{u}, \sigma^{l}\right) 0.3$. For the down state, the probabilities of high and low volatility are the same, i.e., 0.2 and 0.3. In Model 2 (Panel B) change the probabilities (see yellow boxes) to 0.1 and 0.4 in the up state and to 0.3 and 0.2 in the down state. As a result, the index-to-volatility correlation also changes from 0 to -0.41 .

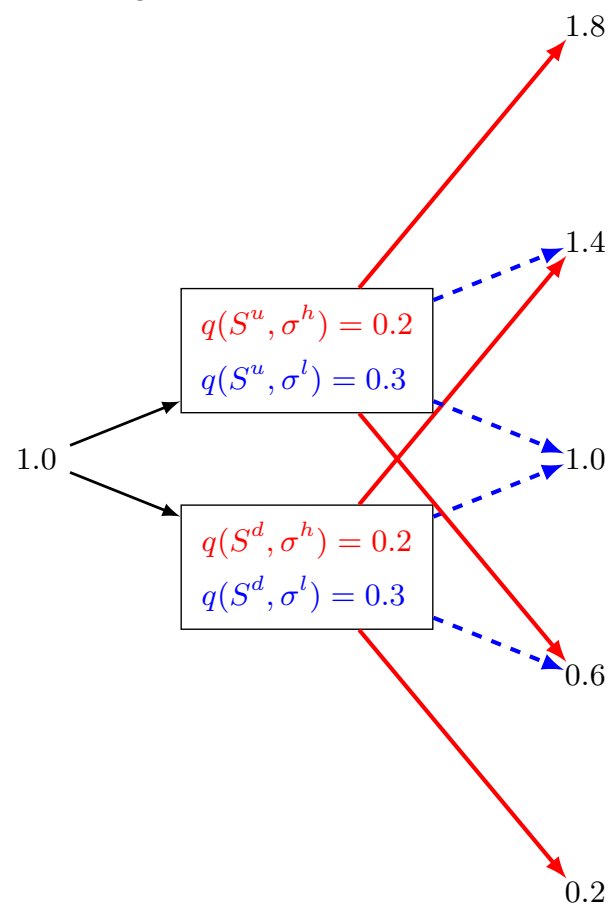

Panel A: Model 1

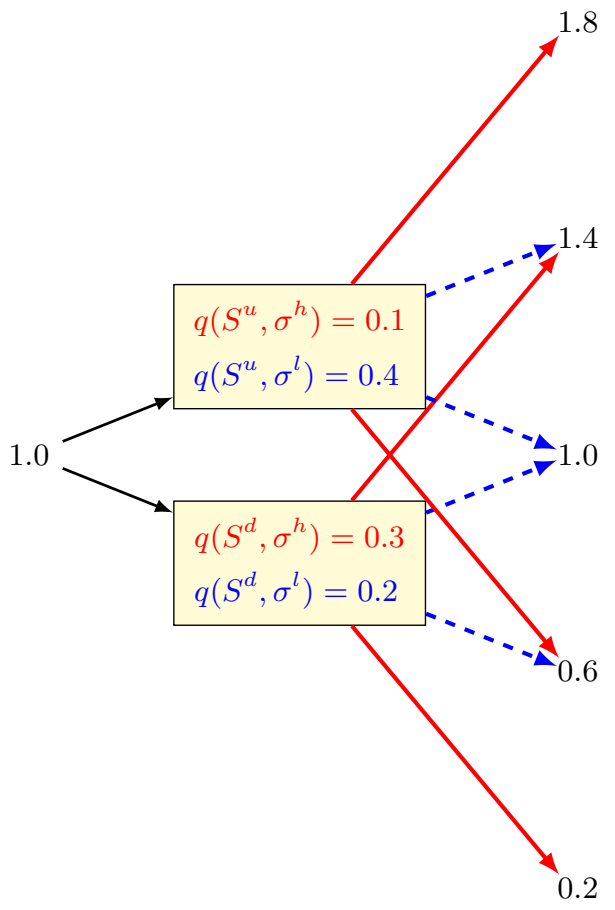

Panel B: Model 2

case of Model (2) as opposed to 0.10 in the uncorrelated case of Model (1). Crash events are more likely over two periods as a more negative implied correlation means that low returns are more likely to be followed by high volatility and thus the far left tail is reached more frequently and becomes "fatter." This behavior is akin to the volatility feedback effect (Bekaert and Wu (2000)), albeit applied to the very left tail of the second-period distribution.

In our empirical work, we reverse engineer the implied correlation coefficient by fitting the model implied two-period distribution to the empirical two-period risk-neutral distribution of returns based on two-month options on the S\&P 500 from July 2007 to August 2014. To find the two-period distribution, we first generate the two marginal distributions of returns and volatility from one period options on the S\&P 500 and VIX. ${ }^{3}$ The dependence structure is

\footnotetext{
${ }^{3}$ Strictly speaking, the distribution of VIX is not the same as the distribution of future expected volatility. However, a number of studies (see Christoffersen, Jacobs, and Chang (2011) for a review) show that option-
} 
modeled by a bivariate copula. ${ }^{4}$ Each value of the dependency parameter of the copula maps into an index-to-volatility correlation. From this information, we can build up the two-period risk-neutral return distribution, which we fit using observed two-period option prices. Details are collected in Section 4.

We find that asymmetric volatility risk, as measured by implied correlation, is important for investors and compensated by a significant correlation risk premium (= implied minus realized correlation) of -0.06 .

Given that investors are concerned about asymmetric volatility risk, how can they possibly hedge that risk? We suggest a trading strategy, consisting of a short calendar spread of out-of-the-money puts liquidated at the expiration date of the short-term option, which gives protection against a volatility spike in case of an extreme negative market return. ${ }^{5}$ Such trading strategy is highly correlated with realized index-to-volatility correlation, delivers on average negative returns, and pays off when the asymmetric volatility effect is especially strong (i.e. when the index-to-volatility realized correlation is very negative).

Implementing that trading strategy for Model 1 with strikes 0.9 (i.e., $10 \%$ out-of-the-money, corresponding to our empirical implementation), we initially obtain 0.05 for the one-period written put and pay 0.145 for the two-period put for a total cost of 0.095 . At time 1 , we liquidate our position. After a positive return (i.e., in the up state $S^{u}$ ) we gain 0.06 from the longer-dated put (the shorter put expires worthless) and after a negative return $\left(S^{d}\right)$ we gain 0.23 from the longer-dated put while paying 0.10 on the short-dated put for a total of 0.13 . Now imagine that, after establishing our hedging strategy at time 0 in Model 1 (implied correlation being 0), we move to Model 2 at time 1 (with index-to-volatility correlation moving negative to -0.41 ). Our liquidated position after a positive return moves down to 0.03 , while it moves up to 0.17 after a negative return. We thus gain in the more vulnerable down state as the hedge was designed to do. Moreover, due to the hedge, we are better off by $0.005=0.5 \times(0.03-0.06)+0.5 \times(0.17-0.13)$ in Model 2 compared to Model 1.

implied volatility predicts future realized volatility extremely well, and so we use the risk-neutral distribution of VIX as a proxy for the risk-neutral distribution of future expected volatility.

${ }^{4}$ We use the Frank (1979) copula, which is particularly well-suited for the typically negative dependence we find in the data, but results are robust to using other (Gaussian, and Student's t) copulas. For the copula selection see Section 4, and for robustness checks see Section 6.

${ }^{5}$ In effect, we simultaneously sell a short-term out-of-the-money put option on the market index and buy a longer-term put option with the same strike. Then we hold the options until the expiry date of the short-term option when we let the first option expire and buy back the longer-term option. 


\subsection{Empirical results}

As implied correlation becomes more negative, we empirically find a higher realized secondperiod volatility and lower realized second-period return. The latter result also holds and becomes stronger conditionally on a negative first-period return. The realized second-period return is lower in that case than in the unconditional case. The volatility feedback story of Bekaert and $\mathrm{Wu}(2000)$ is consistent with these findings related to asymmetric volatility risk. A negative first-period return is followed by an increase in realized volatility, investors demand a higher volatility risk premium which depresses the stock price at $t 2$, and the realized secondperiod return turns out lower.

We establish two new findings, which go beyond the volatility feedback story. More negative implied correlation changes the shape of the second-period risk-neutral distributions. We depict in Figure 2, Panel A, again Model 2 from above. The four conditional second-period risk-neutral distributions emanate at time $t 1$ from the stock prices of 0.8 and 1.2 , further depending on volatility being high or low. In Panel B, we depict the empirical findings. The left tail of the four conditional distributions becomes fatter as it grows in probability from 0.5 to 0.55 while the right tail shrinks accordingly. Our second finding is that, at the same time, the implied skewness of the conditional distributions increases from 0 to some positive value. ${ }^{6}$

We summarize these last two findings in Table 1 where we present unconditional measures of the second-period risk-neutral distribution, which we obtain by calculating the weighted averages of the measures for each conditional distribution. The mean return and volatility stay constant at 0 and 0.36 across all three models. Implied skewness, however, which is 0 in Models 1 and 2, is now 9.53 during the second period. As a final measure, we compute "Right tail minus Left tail" as the probability mass to the right of the $10 \%$ return minus the probability mass to the left of the $-10 \%$ return (which corresponds approximately to the $\pm 2 \sigma$ event if unconditional market volatility is $17 \%$ p.a.). Again, the value is 0 in Models 1 and 2, but Model 3 exhibits a negative value of -0.1 , indicating a shift from the right tail of the distribution to the left tail.

\footnotetext{
${ }^{6}$ We need to shift the final stock prices at time $t 2$ in order to keep the risk-neutral mean at zero.
} 
Figure 2: Illustration 2

The figure shows an example of a stock process over two periods, where the initial stock price of 1 can move to $S^{u}=1.2$ or to $S^{d}=0.8$. The probability of an up-move is 0.5 at $t=0$, and also 0.5 at $t=1$ in all states in Model 2 (Panel A); the probability of an up-move at $t=1$ in Model 3 (Panel B) is 0.45 , while the probability of a down-move is 0.55 . The stock return volatility at $t=1$ can either be high $\left(\sigma^{h}=0.6\right.$, red lines), or low ( $\sigma^{l}=0.2$, blue dotted lines). The joint probability of being at $t=1$ in the up state with high expected probability $\left(S^{u}, \sigma^{h}\right) 0.1$ and in the up state with low expected volatility $\left(S^{u}, \sigma^{l}\right) 0.4$. For the down state, the probabilities of high and low volatility are 0.3 and 0.1 .

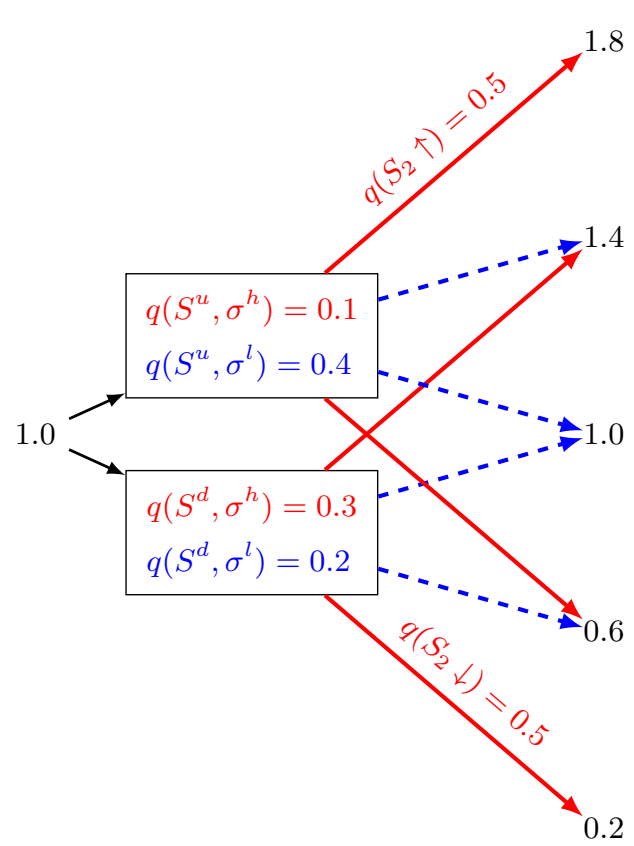

Panel A: Model 2

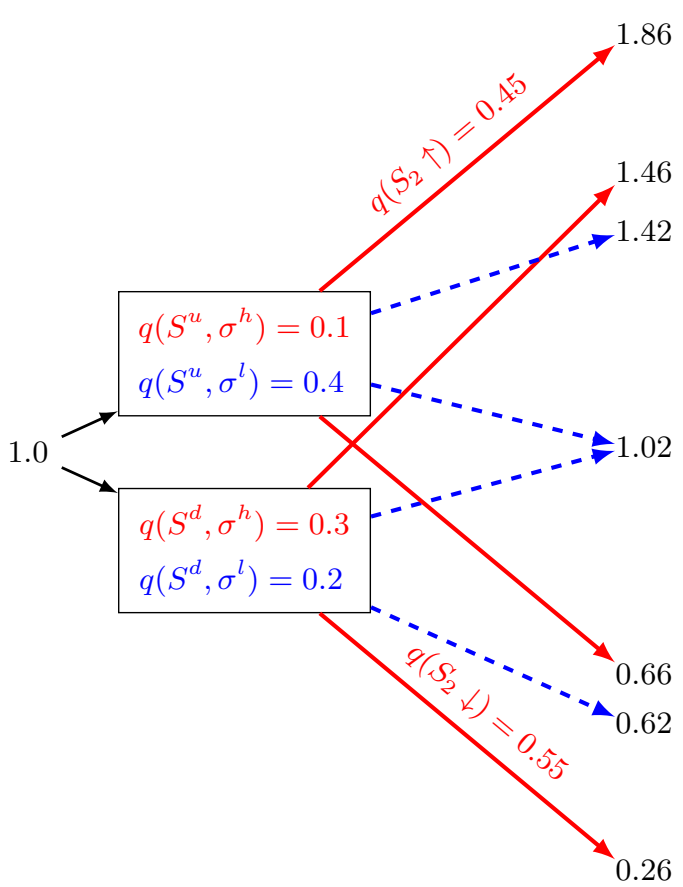

Panel B: Model 3

Table 1: Return distribution parameters for illustrations \#1 and \#2

The table shows the parameters of the unconditional return distribution at $t=1$ for Models 1,2 , and 3. "Right tail minus Left tail" is the probability mass to the right of the $10 \%$ return minus the probability mass to the left of the $-10 \%$ return (which corresponds approximately to the $\pm 2 \sigma$ event if unconditional market volatility is $17 \%$ p.a.).

\begin{tabular}{l|ccc} 
Distribution Parameters & Model 1 & Model 2 & Model 3 \\
\hline Mean return & 0.00 & 0.00 & 0.00 \\
Volatility & 0.36 & 0.36 & 0.36 \\
Skewness & 0.00 & 0.00 & 9.53 \\
Right minus Left tail & 0.00 & 0.00 & -0.10
\end{tabular}

\section{Literature}

We investigate in this paper the relationship of returns and expected future volatility. The information thereabout we back out from option prices and historical prices. This relates us directly to two large areas of research: first, the study of asymmetric volatility which investigates 
the interaction of returns and contemporaneous volatility and, second, the study of recovering information implied in market prices of options and indices.

\subsection{Asymmetric volatility and return predictability}

Black (1976) and Christie (1982) first discussed asymmetric volatility, initially labeled as the leverage effect. Current, state-of-the-art accounts of asymmetric volatility are presented by Bekaert and $\mathrm{Wu}$ (2000) and Dennis, Mayhew, and Stivers (2006) with the main modeling choice that returns and volatility are inversely related to each other, as empirically found in the data. ${ }^{7}$ Andersen, Bondarenko, and Gonzalez-Perez (2015) is one of the latest studies reviewing the problems of estimating the leverage coefficient from the market index and an integrated volatility proxy (e.g., VIX) using high-frequency data. Kalnina and Xiu (2015) provide a theoretical base for such an estimator. Both studies provide justification for our realized indexto-volatility correlation. Trading volatility in such a setting is detailed in Eraker and Wu (2014) and Whaley (2014).

Closely related is the literature on the variance risk premium, which is defined as the riskneutral expectation of index variance minus the realized index variance. It measures the fear of high volatility. Select contributions to this field are Bekaert and Hoerova (2014), Bollerslev, Tauchen, and Zhou (2009), Bollerslev and Todorov (2011), and Carr and Wu (2009). Our point of departure is that variance risk is inherently symmetric, while we explicitly investigate asymmetric volatility which is larger, conditional on a negative versus a positive return of same magnitude.

Some of the variance risk premium papers then go on to predict future returns using the variance risk premium within an ICAPM framework. Chang, Christoffersen, and Jacobs (2012) suggested market skewness as an alternative related factor in this setting. We document in our empirical work, that asymmetric volatility risk is different from the variance and skewness risk.

\footnotetext{
${ }^{7}$ Note that Bekaert and Wu (2000) use realized volatility while Dennis, Mayhew, and Stivers (2006) use implied volatility.
} 


\subsection{Recovering information implied in market prices}

We recover the risk-neutral correlation between returns and future expected volatility by nonparametrically modeling their bivariate distribution. We thereby touch on separately recovering marginal densities of S\&P 500 returns and of future VIX values. While we go on to analyze the joint distribution, there is a large literature on the extraction of risk-neutral marginal densities, e.g., the surveys of Jackwerth (2004) or Christoffersen, Jacobs, and Chang (2011).

Most studies approach the estimation of the risk-neutral correlation between returns and stochastic volatility by resorting to parametric, continuous-time models with constant instantaneous correlation coefficients (e.g., Heston (1993), Christoffersen, Heston, and Jacobs (2009)). Recent papers find that the options on VIX cannot be priced properly using the models fitted to the S\&P 500 index options only (e.g., Fuertes and Papanicolaou (2014), Bates (2012), Bardgett, Gourier, and Leippold (2013), Duan and Yeh (2012), and Carr and Madan (2013)). Mencía and Sentana (2013) show that pricing VIX options requires some non-trivial modeling of the central tendency and the stochastic volatility of volatility.

Several studies propose models, which can simultaneously price equity- and volatility-based derivatives (Branger, Kraftschik, and Völkert (2014) and Song and Xiu (2015) use parametric models, while Chabi-Yo and Song (2013) work out a semi-parametric model with constant historical correlation). Yet none of these papers can identify the risk-neutral correlation as they only study the marginal distributions of returns and volatility since there are no options written on both quantities at the same time (e.g., basket options do not exist).

Our major contribution compared to the above studies is an identifying restriction for calibrating the joint dynamics by going into the time-series dimension. We build up the longdated risk-neutral distribution of returns from the two shorter-term marginal distributions and the implied correlation. Then, we can identify the implied correlation by fitting long-dated market option prices to model prices based on the long-dated distribution.

Moreover, as most existing models in the literature are estimated in an unconditional manner (due to a large number of parameters), they fix the model parameters, including instantaneous correlations, for the whole sample length. We, on the other hand, look at the forward-looking 
correlation of first-period returns with second-period expected volatility and estimate those correlations each week using only currently observable data.

\section{Data and definition of variables}

The CBOE launched options on futures on VIX in 2006, so we start the data collection on this date and end in August 2014. To create our weekly sample, we first find all short-term (one-month) S\&P 500 index option expiration dates. We also collect the matching short-term (monthly) VIX futures option expiration dates and the long-term (two-month) S\&P 500 index option expiration dates, which expire one month later. We then create four observation dates by going back one, two, three, and four weeks from the expiration date of the short-term S\&P 500 option. This procedure gives us about 400 weekly observation dates; however, due to limitations of data quality for VIX options, we drop some early data and select all dates from July 2007 until August 2014, which gives us 345 observations dates in total. Further details can be found in Appendix A.2.

\subsection{Data on the stock market including options}

We obtain end-of-day options data on the S\&P 500 index from OptionMetrics. ${ }^{8}$ We also obtain tick data for S\&P 500 futures from TickData. We work with midpoint implied volatilities inferred from raw option prices. We also record the S\&P 500 dividend yields and interpolate the certificate of deposit rates from OptionMetrics to match the exact days-to-maturity of our S\&P 500 options.

On each observation date, we collect out-of-the-money short-term and long-term S\&P 500 index options, where four related observation dates share the same expiration date as detailed above. We eliminate options with zero bids and filter for moneyness (=strike price/index level) to lie between 0.7 and $1.3 .^{9}$ In order to compute risk-neutral distributions and riskneutral distribution moments, we require at least eight index option prices to exist at any given observation date. We compute model-free implied variance and model-free implied skewness

\footnotetext{
${ }^{8}$ We use the IvyDB OptionMetrics database available through WRDS; updated in December 2014 (as noted on WRDS web-site) until August 2014.

${ }^{9}$ For robustness, we changed the moneyness range from 0.7-1.3 to 0.8-1.2 and results do not change by much. Also, for increased numerical stability, we multiply all moneyness levels by 1000 before applying our calculations and divide by 1000 afterwards.
} 
using Bakshi, Kapadia, and Madan (2003). Following Bollerslev, Tauchen, and Zhou (2009), we compute the variance risk premium for the $\mathrm{S} \& \mathrm{P} 500$ index as the difference between the model-free implied variance for the next month and the realized variance over the past month computed from high frequency data.

\subsection{Data on the market expected volatility}

We obtain end-of-day data on options on futures on VIX from OptionMetrics and daily VIX futures data from the CBOE. We collect the underlying VIX as daily closing data from the CBOE and as intraday data from TickData. We work with midpoint implied volatilities inferred from VIX options. We estimate VIX implied volatilities from the Black (1976) model using raw option prices and the reported VIX futures level at the end of the day, as the implied volatilities reported by OptionMetrics are based on the actual VIX level without adjusting for the cost of carry.

We use the same observation dates as for the S\&P 500 options and collect the short-dated options on futures on VIX. We eliminate zero bids and filter for moneyness (=strike price/VIX futures level) to lie between 0.2 and 3.0. We use only out-of-the-money options. ${ }^{10}$ In order to compute risk-neutral distributions, we require at least five available options on VIX futures.

\section{Methodology}

This paper is about asymmetric volatility risk as measured by the time-varying correlation risk premium. Thus, we first describe how we obtain the realized correlation between return and future expected volatility. Next, we work out the risk-neutral distributions of index returns and future volatility separately. Finally, we connect the two marginal distributions via a copula, which allows us to work out the risk-neutral version of the index-to-volatility correlation implied by options prices. The correlation risk premium is the implied correlation minus the realized correlation.

\footnotetext{
${ }^{10}$ Note that in the case of VIX we go very far out-of-the-money. The reason is that VIX has much higher implied volatility than market index options, and the options on VIX futures are liquid farther away from the at-the-money level.
} 


\subsection{Realized correlation between return and future expected volatility}

To compute the time-varying realized correlation between return and future expected volatility $\left(R C_{t-, t}\right)$ for each observation date (based on the past month of observations), we use the secondbest method (resampling and averaging) of Zhang, Mykland, and Ait-Sahalia (2005) applied to correlation estimation. ${ }^{11}$ This simple-to-use high-frequency correlation estimator is robust to both non-synchronicity (Epps (1979) effect) and noise in the data. Moreover, we compute and compare two versions of unconditional (i.e., for the whole sample) realized correlations. One we base on monthly increments (-0.7356) and the other we base on our high-frequency increments (-0.7358); they are almost identical, and the difference is insignificant. ${ }^{12}$ The small discrepancy indicates that the selected sampling procedure efficiently captures joint jumps in the market index and its integrated volatility, which is necessary for proper estimation of the asymmetric volatility effect (Andersen, Bondarenko, and Gonzalez-Perez (2015)). Hence, we feel justified to use the high-frequency correlation estimation in the further analysis. For details, please see Appendix A.1.2.

\subsection{Marginal risk-neutral distributions for returns and future volatility}

On each observation date, we estimate the short-term risk-neutral distributions of the S\&P 500 returns and of the future expected volatilities using the fast and stable method of Jackwerth (2004), which provides, given a trade-off parameter, a closed-form solution for fitting the implied volatilities of observed options best, while, at the same time, delivering the smoothest implied volatility smile. The same paper argues that, given some low number of observed option prices, the exact choice of method matters little in obtaining risk-neutral distributions. The return distribution is specified by the realizations of net returns, where we normalize returns to have a mean equal to the risk-free rate minus the dividend yield (i.e., the mean of the traded asset return under the risk-neutral measure) and unit variance. We denote this risk-neutral distribution at time $t$ by $\hat{Q}_{t}(m)$, where each discrete density function is defined by a number of values $m_{i}, i=1, \ldots, N$ and their associated probabilities $\hat{Q}_{t}(m)$. Details are in Appendix A.3.

\footnotetext{
${ }^{11}$ A similar "first-best" extension is derived in Zhang (2011) and discussed along with other methods in AitSahalia, Fan, and Xiu (2010).

${ }^{12}$ Using relative changes instead of log changes does not affect the results.
} 
The case of VIX needs extra discussion. Starting on March 26, 2004, the volatility index methodology uses market prices of S\&P 500 out-of-the-money options to compute VIX. The level of VIX can then serve as an approximation of the variance swap rate up to the discretization error and the error induced by jumps (see, e.g., Carr and Wu (2006)). When we extract the risk-neutral density of the future VIX, we obtain the probability distribution of the future 30day expected volatility of the $\mathrm{S} \& \mathrm{P} 500$ index that is due to the diffusion component and not of the total quadratic variation that also includes potential jumps. The arising difference is considered negligible (e.g., Carr and Wu (2009), Jiang and Tian (2005)) and often ignored in empirical analysis (e.g., Todorov and Tauchen (2011)). We thus assume that the shape of the risk-neutral distribution extracted from VIX futures options can be used as a proxy for the shape of the distribution of future expected volatility.

We denote the risk-neutral distribution for the expected future volatility at time $t$ by $\hat{Q}_{t}^{\sigma}\left(m^{\sigma}\right)$, where each discrete density function is defined by a number of values $m_{i}^{\sigma}, i=1, \ldots, N^{\sigma}$ and their associated probabilities $\hat{Q}_{t}^{\sigma}\left(m^{\sigma}\right)$. For the future volatility, the distribution is specified by the relative deviation in future volatility from its expected level, and hence it automatically takes on a mean of one. Details are in Appendix A.4.

\subsection{Joint risk-neutral distribution of first-period returns and future ex- pected volatilities; implied index-to-volatility correlation}

By now, we have the two marginal risk-neutral distributions in place, but not yet the bivariate distribution. We rely on Sklar's (1959) Theorem ${ }^{13}$, that every multivariate cumulative distribution can be represented as a copula function defined over the marginal distributions.

We initially select five copulas - two implicit copulas (Gaussian and Student's t), which are extracted from well-known multivariate distributions but do not have closed-form expressions, and three explicit ones (Frank, Clayton, and Gumbel), which belong to the Archimedean family and have simple closed-form expressions. We select the best copula for modeling dependency between the market return and future volatility by fitting joint distributions (see Table A1, Panel A) under the actual probability measure. Overall, symmetric copulas (Frank, Student's t, and Gaussian) work, while asymmetric ones (Clayton and Gumbel) do not; the Frank copula

\footnotetext{
${ }^{13}$ For example, see page 186 of McNeil, Frey, and Embrechts (2005).
} 
delivers very good performance under the actual probability measure. Details can be found in Appendix A.1.1.

Thus, we also use the Frank copula to generate our risk-neutral distribution. ${ }^{14}$ It will later emerge that this choice also performs best for the risk-neutral distribution, see Table A1, Panel B. The Frank (1979) copula is written as follows:

$$
C_{\theta}\left(u^{1}, u^{2}\right)=-\frac{1}{\theta} \log \left(1+\frac{\left.\left(\exp \left(-\theta u^{1}\right)-1\right)\left(\exp \left(-\theta u^{2}\right)\right)-1\right)}{\exp (-\theta)-1}\right),
$$

where $\theta$ is the dependence parameter and $u^{1}$ and $u^{2}$ are random vectors with uniformly distributed marginal distributions, where each realization of the random vector can be converted into the realizations of the respective variables by using inverse cumulative marginal distributions.

But how do we calibrate the parameter $\theta$ of the Frank copula? The idea is to use the bivariate distribution of returns and future volatilities to build up the long-dated risk-neutral index distribution. We can then change $\theta$ in such a way as to minimize the pricing error of the long-dated S\&P 500 options. We describe this procedure in detail in Appendix A.5 and now discuss only the main ideas.

The copula takes the empirical marginal distributions $\left(\hat{Q}_{t}\right.$ and $\left.\hat{Q}_{t}^{\sigma}\right)$ and the parameter $\theta$ as inputs. It produces a joint risk-neutral distribution $\hat{Q}_{t}\left(r_{t, t_{1}}, \sigma_{t_{1}, t_{2}}\right)$ of the first period (which can be one, two, three, or four weeks) return $r_{t, t_{1}}$ and of the expected volatility $\sigma_{t 1, t 2}$ of the market return in the second period (which is always one month).

We take 200,000 bivariate draws from the copula, which we convert into 200,000 pairs of first period returns and expected second period volatilities. ${ }^{15}$ Based on those draws, we construct a conditional distribution of market return in the second period $\hat{Q}_{t}\left(r_{t 1, t 2} \mid r_{t, t 1}, \sigma_{t 1, t 2}\right)$ by starting with the distribution of normalized market return $m \sim \hat{Q}_{t}$ with mean $r_{f}-\delta$ and volatility 1 from the first period. We adjust its volatility to match the drawn instance of the second period volatility $\sigma_{t 1, t 2}$ and at that time we take care that we scale mean and volatility to account for the number of days between $t 1$ and $t 2$.

Having the second-period returns in place, we create the risk-neutral distribution of twoperiod returns $\hat{Q}_{t}\left(r_{t, t 2}\right)$ by aggregating the returns over the first and the second periods. We

\footnotetext{
${ }^{14}$ We show the (very similar) results for the Gaussian and Student's t copulas in the robustness section.

${ }^{15}$ The numerical procedure converges after approximately 50,000 draws.
} 
then use the two-period risk-neutral distribution to price the long-dated index options. Each set of prices depends on two parameters, namely, the dependency parameter $\theta_{t}$ of the copula and the mean of the future volatility distribution $\bar{\sigma}_{t 1, t 2}$ that we use to rescale the volatility distribution. ${ }^{16}$ We find the optimal parameters by minimizing the pricing error between the theoretical and observed prices. ${ }^{17}$ As the dependence parameter $\theta$ is not directly comparable to the realized correlation computed above, we compute the implied index-to-volatility correlation $\left(I C_{t, t 1}\right)$ based on the optimal parameters and the resulting joint distribution of first-period returns and expected future volatilities.

For each observation date, we define the ex ante implied correlation risk premium $\left(C R P_{t}\right)$ as the difference between the risk-neutral $\left(I C_{t, t 1}\right)$ and realized $\left(R C_{t^{-}, t}\right)$ index-to-volatility estimates, i.e.,

$$
C R P_{t}=I C_{t, t 1}-R C_{t^{-}, t}
$$

By using non-matching periods in formula (2) ( $t^{-}$to $t$ is based on the past month, and $t$ to $t 1$ is based on the time to expiration of the short term option), we follow the definition of the ex ante variance risk premium (as in Bollerslev, Tauchen, and Zhou (2009)) to avoid a forward-looking bias in the empirical analysis. ${ }^{18}$

\section{Empirical results}

We present results on the index-to-volatility correlation, which we interpret as a measure of asymmetric volatility risk, as a significant and priced variable. We relate it to other economically relevant variables and document that it predicts future investment opportunities. In the subsequent analysis we will use the calibration based on the Frank copula, and the other two sets of results (for Gaussian and Student's t copulas) will be left for the robustness section.

\footnotetext{
${ }^{16}$ There is no predetermined value for the expected future volatility since volatility is not an easily traded asset. Thus, we pin it down by calibrating it via the long term index option prices.

${ }^{17}$ We use the root mean-squared error of relative deviation of model-based implied volatility from its observed counterpart. On average, we produce two-period option prices with an error of about $3 \%$ in terms of relative deviation of their implied volatility from observed implied volatility. Alternative choices of root mean squared error or mean absolute error combined with relative or absolute measures combined with implied volatilities or prices yield similar results.

${ }^{18}$ The use of past realized value is justified by the fact that the realized correlation is extremely persistent, with a highly significant $\operatorname{AR}(1)$ coefficient around 0.99 .
} 


\subsection{The index-to-volatility implied correlation and correlation risk premium}

We interpret $\mathrm{CRP}$ as a risk premium, measuring how concerned investors are about the difference of implied versus realized index-to-volatility correlation. Implied index-to-volatility correlation has a mean of -0.81 with a standard error of 0.008 , while realized index-to-volatility correlation has a mean of -0.75 with a standard error of 0.004 . The CRP thus has a mean of -0.06 with a standard error of 0.009 and is strongly significant with a p-value of less than 0.01 . Depicting the two time series of implied and realized index-to-volatility correlation, we see in Figure 3 that both are highly time-varying. The correlation between the two time series is slightly negative at -0.026 which indicates that implied and realized index-to-volatility correlations are not redundant in terms of the information they contain: realized measures typically do not account for the rarely observed tail regions of the return distribution, while implied measures are based on expectations over the whole range of future index returns. Both series are highly persistent, and we fail to reject a unit root using the Augmented Dickey-Fuller test at the $5 \%$ level for realized and at the $10 \%$ level for implied correlation.

Economically, the significance of the CRP means that taking on asymmetric volatility risk is being rewarded in the market. Importantly, the CRP is based on the joint distribution of returns and future volatility, whereas alternative risk measures (e.g. implied volatility, skewness, and the variance risk premium) are based only on the return distribution. We would like to think about correlation risk in terms of a stochastically changing investment opportunity set, and we argue that it tells us something about fears concerning future crashes and their expected duration. Asymmetric volatility risk is the conditional risk of changing distant future investment opportunities depending on the short-term realization of market return. A high risk (i.e., a very negative implied correlation) indicates that a negative first-period return is very likely to be followed by high second-period volatility. The magnitudes of returns and corresponding volatilities, however, are defined by the respective index and expected volatility distributions, as determined from observed option prices. Because of its conditional nature, asymmetric volatility risk does not affect the current short-term risk of the portfolio unless it is costly or impossible to liquidate a position after the first period. 
Figure 3: Index-to-volatility correlation

The figure shows the weekly time series of the implied and realized index-to-volatility correlation over the sample period from July 2007 until August 2014. The graphs have been smoothed by equal weighted averaging over three neighboring observations. Realized index-to-volatility correlation is computed over the period from the observation date until the maturity of the short-term options used in calibration.

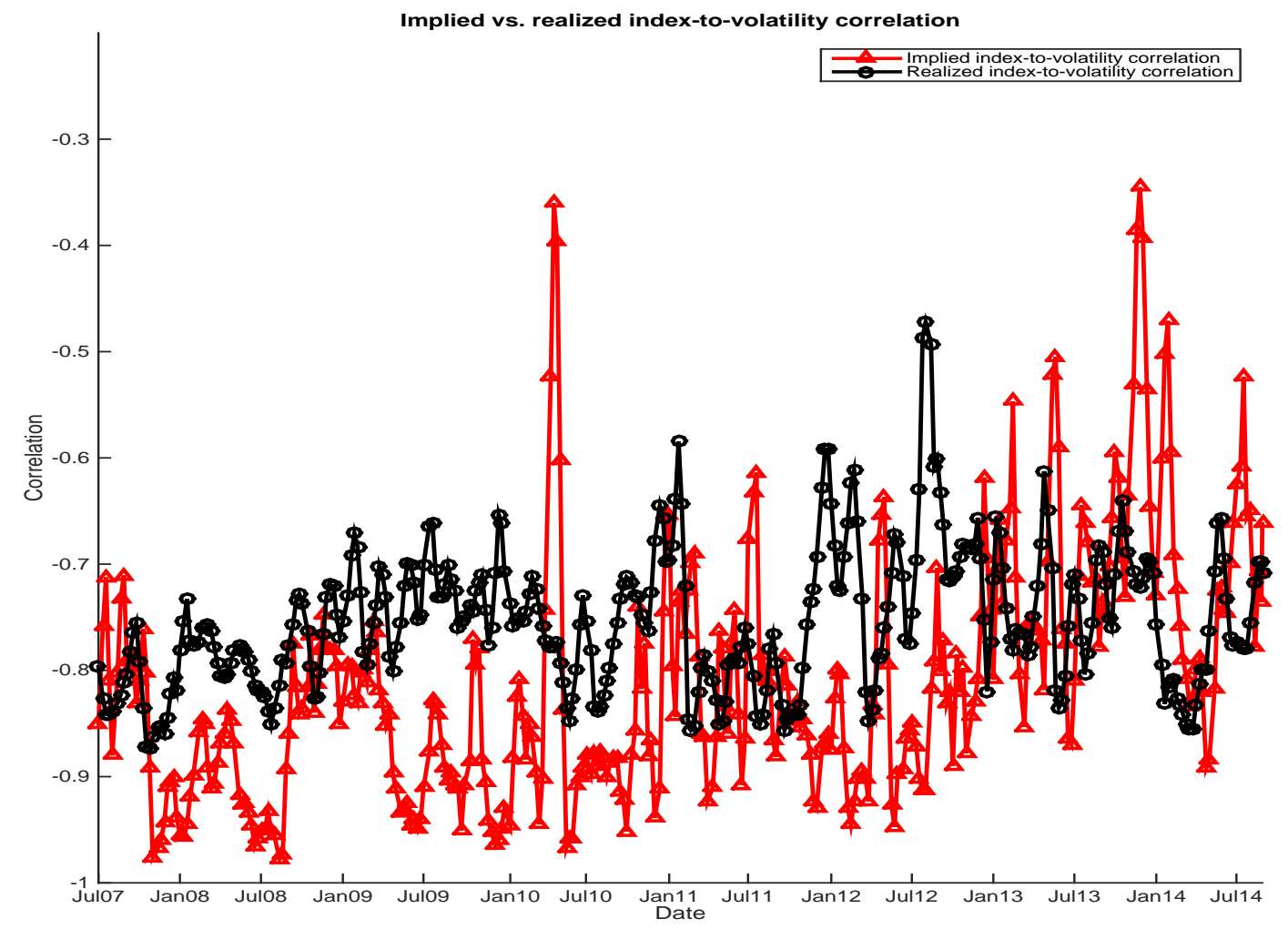

\subsection{Implied index-to-volatility correlation versus other variables}

In exploring index-to-volatility correlation risk, we compare the implied index-to-volatility correlation and risk premium to various variables which could be affected by the interplay of index return and future expected volatility. To do so, we report correlations across eight variables in Table 2. The index-to-volatility implied correlation and the correlation risk premium are highly correlated (0.90), and in the following we always talk about IC.

The variance risk premium (VRP) is the payment for a hedge against negative returns by gaining on increased volatility. Inherently, the VRP is symmetric as an up or down move (of same size and relative to the mean) results in the same contribution to variance. ${ }^{19} \mathrm{~A}$

\footnotetext{
${ }^{19}$ Bollerslev and Todorov (2011) claim that the VRP is mostly driven by jumps and not the diffusive part of the returns. However, their measures of jumps for the left tail and the right tail are correlated to a very high degree. Our argument that the VRP is mainly about symmetric tail risks thus remains valid.
} 
Table 2: Correlations

The table shows the correlations between the implied index-to-volatility correlation, the correlation risk premium, the variance risk premium, VIX, long-term minus short-term option implied skewness, shortterm option implied skewness, the realized S\&P 500 return from $t$ to $t 1$ (Market return, first period), and the realized S\&P 500 return from $t 1$ to $t 2$ (Market return, second period). The sample period is July 2007 until August 2014. All variables but the market returns are known on the observation date.

\begin{tabular}{lc|ccccccc} 
Variable & $\#$ & 1 & 2 & 3 & 4 & 5 & 6 & 7 \\
\hline Index-to-vol Impl Corr & 1 & 1.00 & & & & & & \\
Index-to-vol Corr Premium & 2 & 0.90 & 1.00 & & & & & \\
Variance Risk Premium & 3 & -0.02 & -0.04 & 1.00 & & & & \\
VIX & 4 & -0.20 & -0.13 & 0.01 & 1.00 & & & \\
Implied Skewness, long-short & 5 & 0.37 & 0.30 & -0.04 & -0.37 & 1.00 & & \\
Implied Skewness, short & 6 & -0.39 & -0.32 & 0.05 & 0.57 & -0.89 & 1.00 & \\
Market return, first period & 7 & -0.08 & -0.10 & 0.29 & -0.11 & 0.05 & -0.06 & 1.00 \\
Market return, second period & 8 & 0.15 & 0.09 & 0.03 & 0.08 & -0.08 & 0.02 & 0.01
\end{tabular}

first indication that IC is measuring something different from the VRP can be found in the low correlation with the VRP of only -0.02. Our economic intuition is that IC is an asymmetric and conditional risk measure. A more negative IC worsens the conditional investment opportunity set by strengthening the relationship between a negative first period shock and a more volatile second period return.

As a second symmetric risk measure, we consider the VIX which is often referred to as a market fear gauge. It is virtually uncorrelated with the VRP (0.01) but negatively with IC $(-0.20)$. Thus, we expect VIX to rise whenever IC is more negative.

A negative index-to-volatility correlation affects the two-period index return distribution through the left tail in that a negative first-period return induces high volatility during the second period and thus enlarges the left tail. The effect is weaker for the right tail. We thus include as variables the implied skewness from short-maturity options and implied skewness from long-maturity options minus implied skewness over the short period. Both skewness measures are correlated with IC with absolute correlations of up to 0.39 , and they are also highly correlated with each other (-0.89). We concentrate on implied skewness over the long period minus skewness over the short period henceforth, as it more closely mirrors the intuition of IC in relating first period skewness to two-period skewness.

We finally observe that IC is negatively correlated with the first-period market return $(-0.08)$ and positively with the second-period return (0.15). This suggests that IC might be capable 
of predicting market returns, especially more distant ones; we next investigate this exciting proposition further. Since we find IC to be economically related to VIX, the VRP, and long term minus short term skewness, although correlations tend to be moderate, we will use those variables as controls in our further explorations.

\section{3 (Conditional) prediction of the future investment opportunities}

Implied index-to-volatility correlation is unique, compared to other moments of return (e.g., volatility or skewness), in that it describes a behavior of the market index in the distant future depending on its return in the short term. For our investigation of this relation, we perform two different tests: (i) Predicting first- and second-period S\&P 500 realized returns and volatilities, and (ii) Predicting second-period option-implied expected risk measures and moments.

\section{(i) Predicting S\&P 500 returns and volatilities}

In our regression analysis, we start with predicting first-period ( $t$ to $t 1$ ) returns and volatility with the time $t$ implied index-to-volatility correlation while controlling for VIX, the variance risk premium, and the difference in long- and short-term implied skewness. ${ }^{20}$ Implied correlation does not predict either first-period return or volatility, and we do not show the results as a table. The point estimate of the coefficient for first-period return is negative, consistent with our view of IC as a conditional risk indicator - a more negative correlation indicates a higher future risk, and investors who cannot quickly rebalance their portfolios are compensated by higher returns.

Next, we regress second-period ( $t 1$ to $t 2)$ returns and volatility on the same explanatory variables. Results are presented in Table 3, and we see that IC indeed predicts the change in future investment opportunities. A more negative IC is associated with significantly lower future returns and higher volatility; moreover, IC remains significant in the return regression even after including controls, while it loses significance in the volatility regression after controlling for VIX. This finding is not surprising since IC and VIX are negatively correlated (i.e., more negative IC

\footnotetext{
${ }^{20}$ In all tests (i), we use overlapping observations, i.e., we predict some quantity computed over the same period on average four times. Thus, we use Newey and West (1987) standard errors adjusted for autocorrelation with four lags.
} 
is typically accompanied by a higher VIX) and as VIX is probably the best standalone predictor of future volatility. ${ }^{21}$

Table 3: Predicting second-period S\&P 500 performance

We define our dependent variables as second-period realized return and volatility, measured from the expiry of the nearest maturity options until the expiry of the longer-term options. Realized volatility is computed from high-frequency returns. Independent variables are the index-to-volatility implied correlation, VIX, the variance risk premium, and the difference between long-and short-term implied skewness. The p-values are based on the Newey and West (1987) standard errors with four lags.

\begin{tabular}{l|ccc|ccc} 
& \multicolumn{3}{|c|}{ Return } & \multicolumn{3}{c}{ Volatility } \\
\hline & $(1)$ & $(2)$ & $(3)$ & $(4)$ & $(5)$ & $(6)$ \\
Intercept & 0.592 & 0.795 & 0.877 & 0.076 & 0.009 & 0.141 \\
p-val & 0.000 & 0.000 & 0.000 & 0.010 & 0.571 & 0.000 \\
Implied Correlation & 0.656 & 0.938 & 0.920 & -0.127 & -0.045 & -0.074 \\
p-val & 0.002 & 0.000 & 0.000 & 0.001 & 0.360 & 0.081 \\
VIX & - & 0.416 & - & - & 0.588 & - \\
p-val & - & 0.765 & - & - & 0.000 & - \\
Variance Risk Premium & - & - & 0.529 & - & - & -0.328 \\
p-val & - & - & 0.416 & - & - & 0.590 \\
Implied Skewness, long-short & - & -0.193 & -0.224 & - & 0.000 & -0.047 \\
p-val & - & 0.012 & 0.002 & - & 0.026 & 0.000 \\
\hline Adjusted $R^{2}$ & $1.9 \%$ & $4.0 \%$ & $3.7 \%$ & $2.5 \%$ & $31.0 \%$ & $6.0 \%$
\end{tabular}

Further, we want to understand how the link between IC and realized second-period return depends on realized first-period return. Following our intuition about IC as a measure of asymmetric volatility risk, we expect a stronger market reaction in the second period to a given IC conditional on a negative return in the first period. Thus, we define a dummy variable $D_{r<0}$, which is equal to 1 whenever the first-period return is negative and 0 otherwise. The following regression allows us to separate the conditional IC effects:

$$
r_{t 1, t 2}=\beta_{0}+\beta_{1} D_{r<0}+\beta_{2} * I C+\beta_{3} I C * D_{r<0}+\text { controls }
$$

The coefficient $\beta_{2}$ in regression (3) quantifies the baseline effect of IC conditional on a positive first-period return, and $\beta_{3}$ gives the incremental effect of a negative first-period return. After including VIX (or alternatively VRP) and the difference between long- and short-term implied skewness as controls, we obtain a significant baseline $\beta_{2}=0.52$ with a p-value of 0.03 , and a significant incremental effect $\beta_{3}=0.87$ with a p-value of 0.05 . Thus, the second-period return impact of a more negative index-to-volatility correlation (i.e., stronger asymmetric volatility risk) is being amplified by a negative first-period return.

\footnotetext{
${ }^{21}$ Realized first-period correlation, i.e., the realized counterpart to implied correlation, significantly predicts second-period realized volatility even with controls.
} 


\section{(ii) Predicting second period option-implied risk measures and moments}

After predicting second-period realized quantities, we now predict second-period (i.e., observed at time $t 1$ and inferred from the risk-neutral probability distribution for the period $t 1$ to $t 2$ ) riskneutral quantities, namely, the difference between the probability mass in the right tail and the left tail of the distribution, implied skewness, and implied volatility. We use a $\pm 2 \sigma$ threshold for identifying the tail regions, which corresponds to about $\pm 10 \%$ return per month (using an unconditional market volatility of $17 \%$ p.a.). As explanatory variables, we use IC, while controlling for VIX, the variance risk premium, and long- minus short-term implied skewness. ${ }^{22}$

Our results in Table 4 suggest that a more negative IC redistributes future probability mass from the right to the left tail, i.e., an expectation of a stronger asymmetric volatility risk predicts a fatter left tail of the market index distribution in the future (at $t 1$ ); in regression (1) of Table 4, IC alone explains $9.2 \%$ of the changes in the tail probability. Adding VIX and the difference between long- and short-term implied skewness as controls keeps IC significant and raises the adjusted $R^{2}$ to $16.6 \%$. Strikingly, in regression (4), a more negative IC predicts a less negative future implied skewness estimated at $t 1$ and explains $10.8 \%$ of its variability in terms of adjusted $R^{2}$. This significance is lost though, once we add controls in regressions (5) and (6). IC does not predict second-period implied volatility. ${ }^{23}$

Summarizing, a more negative IC observed at $t$ is associated with higher realized secondperiod volatility and a lower realized second-period return; moreover, the realized second-period return is even lower conditional on a negative first-period return. These findings related to asymmetric volatility risk are also consistent with the volatility feedback story of Bekaert and $\mathrm{Wu}$ (2000). After a negative first-period return, (implied and realized) volatility shoots up, and investors demand a higher volatility risk premium, depressing stock prices at $t 2$, and resulting in lower second-period returns.

Two new findings related to asymmetric volatility risk go beyond the volatility feedback story. More negative IC is associated with significantly higher expected tail risk for the next period (starting at $t 1$ ), measured by the difference in right and left tail probabilities, and with higher implied skewness. We thus document a complex distortion of second-period risk-neutral

\footnotetext{
${ }^{22}$ We use non-overlapping regressions to guarantee that the quantity we want to predict is always observed about one month after the estimation date $t$. We use White (1980) standard errors adjusted for heteroscedasticity.

${ }^{23}$ Replacing implied correlation by its realized counterpart (realized correlation from $t$ to $t 1$ ) improves the significance slightly and keeps the direction of relationship unchanged.
} 
Table 4: Predicting second period risk-neutral quantities for S\&P 500

We use as dependent variables the selected characteristics of the option-implied distribution of S\&P 500 estimated on the expiry date $t 1$ of the short-term options that are used to calibrate the index-tovolatility implied correlation at time $t$. The dependent variables are the "Right tail minus Left tail" variable computed as the probability mass to the right of the $10 \%$ monthly return minus the probability mass to the left of the $-10 \%$ monthly return (which corresponds approximately to the $\pm 2 \sigma$ event if unconditional market volatility is $17 \%$ p.a.) and implied skewness and volatility that are computed from the estimated risk-neutral density. Independent variables are the index-to-volatility implied correlation, VIX, the variance risk premium, and the difference between long-and short-term implied skewness. We use non-overlapping regressions to guarantee that the quantity we want to predict is always observed about one month after the estimation date $t$. For p-values we use White (1980) standard errors adjusted for heteroscedasticity.

\begin{tabular}{l|ccc|ccc|ccc} 
& \multicolumn{3}{|c|}{ Right } & minus & Left tail & \multicolumn{3}{|c|}{ Implied skewness } & \multicolumn{3}{c}{ Implied volatility } \\
\hline & $(1)$ & $(2)$ & $(3)$ & $(4)$ & $(5)$ & $(6)$ & $(7)$ & $(8)$ & $(9)$ \\
Intercept & 0.003 & -0.026 & -0.006 & -2.699 & -2.159 & -1.454 & 0.047 & 0.023 & 0.083 \\
p-val & 0.334 & 0.259 & 0.600 & 0.000 & 0.000 & 0.000 & 0.001 & 0.180 & 0.000 \\
Implied Correlation & 0.047 & 0.036 & 0.038 & -1.374 & -0.299 & -0.164 & -0.021 & 0.005 & 0.015 \\
p-val & 0.007 & 0.035 & 0.039 & 0.001 & 0.733 & 0.795 & 0.317 & 0.609 & 0.754 \\
VIX & - & 0.065 & - & - & 2.474 & - & - & 0.210 & - \\
p-val & - & 0.067 & - & - & 0.000 & - & - & 0.000 & - \\
Variance Risk Premium & - & - & -0.056 & - & - & 3.156 & - & - & 0.158 \\
p-val & - & - & 0.587 & - & - & 0.319 & - & - & 0.963 \\
Implied Skewness, long-short & - & 0.018 & 0.009 & - & -0.852 & -1.190 & - & -0.006 & -0.035 \\
p-val & - & 0.058 & 0.517 & - & 0.000 & 0.000 & - & 0.654 & 0.000 \\
\hline Adjusted $R^{2}$ & $9.2 \%$ & $16.6 \%$ & $8.6 \%$ & $10.8 \%$ & $55.6 \%$ & $40.3 \%$ & $0.0 \%$ & $59.8 \%$ & $10.5 \%$
\end{tabular}

distributions in reaction to more negative IC. The left tail grows fatter at the cost of the right tail but, at the same time, probability mass is being shifted closer to the mean in the opposite direction. That keeps the mean constant at the riskfree rate but increases implied skewness.

\subsection{Trading Strategy}

We interpret a more negative implied index-to-volatility correlation (and thus a more negative correlation risk premium) as a more pessimistic investor attitude towards the future joint dynamics of market return and future expected volatility. To hedge against the more negative IC, one wants to be long second-period volatility if the stock is going down over the first period and to be short second-period volatility if the stock is going up. As such conditional trading strategy is not easily implementable using the index itself or futures on the index, we suggest the following option strategy.

Create simultaneously two positions in out-of-the-money put options: sell a short-dated put and buy a long-dated put, and then liquidate the position in the long-dated put on the first 
expiration date. ${ }^{24}$ If we have a positive first-period return, then the short put expires worthless, and we can keep the proceeds from the sale, while the long-dated put loses value through three channels: time decay, negative delta (sensitivity to the price of the underlying), and positive vega (sensitivity to volatility). If we experience a market crash so that the sold put expires in-the-money, then the long-dated put will suffer from time decay but will gain value from much higher implied volatility, and this value boost is positively related to asymmetric volatility risk (i.e., more negative IC). ${ }^{25}$

Empirically, we build a new portfolio of options on each calibration date using out-ofthe-money put options with moneyness of 0.9 (the same threshold that we used for the tail probability computations in Section 5.3). We compute the price of the portfolio for each observation date and its payoff on the first expiration date, and we can then compute the holding period return. The trading strategy loses on average $10.37 \%$ per month and delivers a Sharpe ratio of -0.60 in monthly terms.

We regress the return of the trading strategy on the realized correlation while controlling for VIX, the variance risk premium, and the difference between long- and short-term implied skewness. The strategy performs as expected. We observe in Table 5 that the strategy return is significantly linked to realized correlation, which alone explains more than $14 \%$ of the variation in strategy return. Adding controls does not much improve the explained percentage of variation. ${ }^{26}$ The strategy pays off when asymmetric volatility risk is very pronounced and realized correlation is very negative. Repeating the above regressions with ex post CRP instead of realized correlation works much the same, but the adjusted $R^{2}$ decreases to $6 \%$.

\subsection{Bivariate distribution of returns and volatilities}

As we have estimates in hand of the bivariate distribution of returns and future expected volatility, we can price basket options written on a combination of the two quantities. The risk-neutral correlation between the two quantities could also inform the risk management of banks holding assets linked to market returns and volatility. Furthermore, the time-varying

\footnotetext{
${ }^{24}$ We use the same moneyness for both puts. Then the long-dated put will cost more to buy than the proceeds from selling the short-dated put.

${ }^{25}$ Intermediate first-period returns will lead to some mixture of the described extreme settings.

${ }^{26}$ If we regress not the return, but the cost of the hedging strategy on a set of explanatory variables, IC alone explains almost $15 \%$ in terms of adjusted $R^{2}$, while the difference between long- and short-term skewness is not significant. Adding VIX keeps IC significant and boosts adjusted $R^{2}$ to almost $60 \%$.
} 
Table 5: Asymmetric Volatility Trading Strategy

We define our dependent variable as the return of a trading strategy providing a hedge against asymmetric volatility risk: on each weekly observation date, we sell a short-dated put and buy a long-dated put and then liquidate the position in the long-dated put on the first expiration date. Independent variables are the index-to-volatility realized correlation, VIX, the variance risk premium, and the difference between long-and short-term implied skewness. The p-values are based on the Newey and West (1987) standard errors with four lags.

\begin{tabular}{lccc} 
& $(1)$ & $(2)$ & $(3)$ \\
\hline Intercept & -0.125 & -0.121 & -0.121 \\
p-val & 0.000 & 0.000 & 0.000 \\
Realized Correlation & -0.162 & -0.158 & -0.158 \\
p-val & 0.000 & 0.000 & 0.000 \\
VIX & - & -0.001 & - \\
p-val & - & 0.056 & - \\
Variance Risk Premium & - & - & -0.004 \\
p-val & - & - & 0.110 \\
Implied Skewness, long-short & - & -0.006 & -0.006 \\
p-val & - & 0.325 & 0.211 \\
\hline Adjusted $R^{2}$ & $14.4 \%$ & $14.6 \%$ & $14.6 \%$
\end{tabular}

nature of our findings suggests a time-varying and priced role for index-to-volatility correlation.

This is relevant for the development of stochastic volatility option pricing models, which mostly model index-to-volatility correlation as a constant and do not consider a price of risk for that correlation.

\section{Robustness}

In addition to the reported analysis, we run a series of robustness checks, where we verify that our results survive various changes in the procedures.

First, since we use the Frank (1979) copula in the main part of the paper, we try a number of alternative copulas to model the dependency between the S\&P 500 return and its future expected volatility (VIX). The Frank, the Gaussian, and Student's t copulas deliver comparable fits to historical data, while the Frank copula outperforms the other two slightly in terms of fitting option data. Two further copulas (Clayton and Gumbel) deliver worse fits to both historical and options data. Details are in Section A.1.1.

The index-to-volatility implied correlations produced by the first three copulas (see Figure IA1 in the internet appendix) are all very negative, and the correlation risk premium is 
-0.06 for the Frank copula, while it is even larger for the Gaussian $(-0.08)$ and Student's t $(-0.10)$ copulas. Implied correlations produced by these three copulas are highly correlated in the time series - the correlation coefficients of the Frank copula with the other two are 0.72 and 0.75, while the Gaussian and Student's t copulas have a correlation coefficient of 0.95. We thus expect the implied correlations from these copulas to perform similarly in the predictive tests.

We confirm our expectation by reproducing the prediction tests of future investment opportunities (realized returns, realized volatilities, and expected risk-neutral moments) from Section 5.3 using the Student's t and Gaussian copulas. The results are provided in Tables IA1 and IA2 in the internet appendix. We observe that performance of all three copulas is very similar for predicting realized second-period S\&P 500 returns and volatility - the coefficients have the same magnitudes; the adjusted $R^{2}$ are slightly higher for the Student's t and Gaussian copulas, and the significance of IC in the volatility prediction improves. Now, even controlling for VIX, IC is significant at the $10 \%$ level (p-value of 0.07 for the Student's t and 0.057 for the Gaussian copula). The results for predicting second-period risk-neutral moments are also very similar. Two notable differences exist. In the tail regression (Right minus Left tail), the Frank copula alone (i.e., without controls) shows a higher adjusted $R^{2}$ of $9.2 \%$ compared to the Student's t $(6.3 \%)$ and Gaussian (3.6\%) copulas. In the implied skewness regression, the Gaussian copula alone demonstrates a much higher adjusted $R^{2}$ of $20.7 \%$ compared to the Student's t (8.0\%) and Frank (10.8\%) copulas. These differences open a venue for future research on the exact form of the bivariate risk-neutral distribution of return and future volatility.

As a second robustness check, we introduce a number of additional controls for our regressions. We estimate the Amihud (2002) liquidity measure using returns and volume information for the market exchange-traded fund (SPY) on each observation day for the past month (21 trading days). We further use data on all call and put options on the SPY to compute two proxies of market sentiment, namely the Put-Call Open Interest Ratio and the Put-Call Volume Ratio. On each observation date, we do so by recording the open interest (volume) of all put options on the SPY with maturity between eight days to one year and dividing it by the open interest (volume) of all call options with the maturity within the same range. We finally compute the Momentum sentiment measure as the current price deviation of the market 
index from the 125-day moving average price. ${ }^{27}$ We reproduce the prediction tests of future investment opportunities (realized returns and volatilities) from Section 5.3, while adding these regressors as controls. The results are provided in Table IA3. Comparing the coefficients on IC with the coefficients from the original Table 3, we do not observe any economically significant changes. In our regressions for predicting second period returns, IC is always significant and the new controls barely affect the results. We conclude that, given the controls we use, we have very stable estimates of our models for predicting future returns. We do not reproduce the regressions for predicting risk-neutral moments with controls, because these regressions suffer from severe collinearity problems - newly introduced regressors are highly correlated with old regressors and with the risk-neutral moments on the left-hand side. ${ }^{28}$

As a third control, we split the sample into two equal parts, where the first part (from 07/2007 until 12/2010) includes the turbulent period of the financial crisis of 2008-2009 and where the second half (from 01/2011 until 08/2014) is relatively calm. We reproduce the prediction tests of future investment opportunities (realized returns and volatilities) from Section 5.3 for both subsamples and provide the results in Table IA4. We observe that the significance of the regressors in the return predictability is slightly better for the second half of the sample, though IC remains significant in both subsamples. Moreover, in the second half of the sample, IC predicts second period volatility much better (with a p-value of less than 0.03 in the univariate regression vs. being insignificant) than in the first half. The regression now has an adjusted $R^{2}$ of $4.2 \%$ compared to $2.5 \%$ for the whole sample.

We also reproduce the regressions to predict risk-neutral moments for the two subsamples and also for a longer subsample starting in 03/2009 and lasting until the end of the sample period. The results are provided in Table IA5. Overall, predictability works well for the later period (Panel B) and, in general, for the period after the financial crisis (i.e., after 02/2009, reported in Panel C). In the period including the turbulent times of 2008 and 2009 (Panel A), the predictive regressions suffer from too much noise in the risk-neutral data; moreover, in the tail predictability regressions, VIX even changes sign from negative (for the whole sample and

\footnotetext{
${ }^{27}$ The option-based sentiment measures and the momentum as computed above are parts of the "Fear \& Greed Index," a sentiment index computed by CNNMoney, and available at money.cnn.com/data/fear-and-greed/.

${ }^{28}$ For example, we cannot use together VIX, skewness, Amihud liquidity measure, and momentum. Using only one of these regressors in combination with IC and other controls does not change the significance of IC. We note, however, that the Amihud liquidity measure improves the adjusted $R^{2}$ in the tail regression from about $9 \%$ to more than $30 \%$.
} 
the two later subsamples) to positive. IC keeps its positive sign in the univariate prediction of the tail variable (but loses significance) and changes its sign to positive in the regressions for skewness and volatility. During the crisis subsample, expectations of risks become too volatile to be effectively predicted.

Thus, our main results for implied index-to-volatility correlation are robust to a number of changes in the procedures.

\section{Conclusion}

In our exploration of asymmetric volatility risk, we began by measuring the realized correlation between S\&P 500 index returns and future realized volatility. Using a novel identification strategy, we manage also to work out its risk-neutral counterpart, the implied index-to-volatility correlation, from short-dated options on futures on VIX and short- and long-dated index options. We interpret implied correlation as a measure of asymmetric volatility risk which concerns future investment opportunities conditional on a short-term market return. In particular, a more negative implied correlation predicts a lower second-period return and is also associated with a higher second-period volatility. It further predicts second-period risk-neutral quantities, namely a more positive skewness and a higher probability of a future market crash (tail probability). The higher probability of a market crash worsens the outlook of an investor conditional on experiencing a negative market return in the short run. The correlation risk premium (implied minus realized correlation) is significantly different from zero, and, hence, asymmetric volatility risk is priced in the market.

The feature of implied correlation being a conditional risk measure is unique and extends our understanding of the well-known volatility feedback effect. Expectation of higher asymmetric volatility risk (i.e., more negative implied correlation) exacerbates the feedback effect. Conditional on a negative short-term market return, we observe a significantly lower return in the next period for more negative implied correlation. Such lower return could stem from a market price adjustment after two periods, reflecting an increased risk premium for the higher tail risk. Conditional risk in the future poses a real risk for investors if they face portfolio constraints (or illiquidity) and cannot rebalance during the first period. 
The predictability of the future investment opportunity set and especially conditional risk predictability are new findings. We believe that the latter is an important hallmark of asymmetric volatility risk. A trading strategy of selling short-dated and buying long-dated out-ofthe-money puts hedges against asymmetric volatility risk.

Our work provides new ideas for risk management and the pricing of portfolios of index and/or volatility related securities. In the future, we intend to look at bivariate pricing kernels and asset pricing tests, which could use index-to-volatility correlation as factors. 


\section{References}

Aït-Sahalia, Y., J. Fan, and D. Xiu, 2010, "High-Frequency Covariance Estimates With Noisy and Asynchronous Financial Data," Journal of the American Statistical Association, 105(492), 1504-1517.

Amihud, Y., 2002, "Illiquidity and Stock Returns: Cross-section and Time-series Effects," Journal of Financial Markets, 5(1), 31 - 56.

Andersen, T. G., O. Bondarenko, and M. T. Gonzalez-Perez, 2015, "Exploring Return Dynamics via Corridor Implied Volatility," Review of Financial Studies.

Bakshi, G. S., N. Kapadia, and D. B. Madan, 2003, "Stock Return Characteristics, Skew Laws, and the Differential Pricing of Individual Equity Options," The Review of Financial Studies, 16(1), 101-143.

Bardgett, C., E. Gourier, and M. Leippold, 2013, "Inferring Volatility Dynamics and Risk Premia from the S\&P 500 and VIX Markets," Working Paper University of Zurich.

Bates, D. S., 2012, "U.S. Stock Market Crash Risk, 1926-2010," Journal of Financial Economics, 105(2), 229-259.

Bekaert, G., and M. Hoerova, 2014, "The VIX, the Variance Premium and Stock Market Volatility," Journal of Econometrics, 183(2), 181-192.

Bekaert, G., and G. Wu, 2000, "Asymmetric Volatility and Risk in Equity Markets," Review of Financial Studies, 13(1), 1-42.

Black, F., 1976, "The Pricing of Commodity Contracts," Journal of Financial Economics, $3(1-2), 167-179$.

Black, F., and M. Scholes, 1973, "The Pricing of Options and Corporate Liabilities," Journal of Political Economy, 81(3), 637-654.

Bollerslev, T., G. Tauchen, and H. Zhou, 2009, "Expected Stock Returns and Variance Risk Premia," Review of Financial Studies, 22(11), 4463-4492.

Bollerslev, T., and V. Todorov, 2011, "Tails, Fears, and Risk Premia," The Journal of Finance, $66(6), 2165-2211$.

Bowman, A. W., and A. Azzalini, 1997, Applied smoothing techniques for data analysis: the kernel approach with S-Plus illustrations. Oxford University Press.

Branger, N., A. Kraftschik, and C. Völkert, 2014, "The Fine Structure of Variance: Consistent Pricing of VIX Derivatives," Working Paper Münster University.

Carr, P., and D. B. Madan, 2013, "Joint Modeling of VIX and SPX Options at a Single and Common Maturity with Risk Management Applications," Working Paper New York University.

Carr, P., and L. Wu, 2006, "A Tale of Two Indices," Journal of Derivatives, 13(3), 13-29.

— , 2009, "Variance Risk Premiums," Review of Financial Studies, 22(3), 1311-1341. 
Chabi-Yo, F., and Z. Song, 2013, "Recovering the Probability Weights of Tail Events with Volatility Risk from Option Prices," Working Paper Board of Governors of the Federal Reserve System.

Chang, B. Y., P. Christoffersen, and K. Jacobs, 2012, "Market Skewness Risk and the CrossSection of Stock Returns," Journal of Financial Economics, 107(1), 46-68.

Christie, A. A., 1982, "The Stochastic Behavior of Common Stock Variances: Value, Leverage and Interest Rate Effects," Journal of Financial Economics, 10(4), 407-432.

Christoffersen, P., S. Heston, and K. Jacobs, 2009, "The Shape and Term Structure of the Index Option Smirk: Why Multifactor Stochastic Volatility Models Work So Well," Management Science, 55(12), 1914-1932.

Christoffersen, P., K. Jacobs, and B. Y. Chang, 2011, "Forecasting with Option Implied Information," CREATES Research Papers.

Dennis, P., S. Mayhew, and C. Stivers, 2006, "Stock Returns, Implied Volatility Innovations, and the Asymmetric Volatility Phenomenon," Journal of Financial and Quantitative Analysis, 41(02), 381-406.

Duan, J.-C., and C.-Y. Yeh, 2012, "Price and Volatility Dynamics Implied by the VIX Term Structure," Working Paper National University of Singapore (NUS) - Business School and Risk Management Institute.

Epps, T. W., 1979, "Comovements in Stock Prices in the Very Short Run," Journal of the American Statistical Association, 74(366), 291-298.

Eraker, B., and Y. Wu, 2014, "Explaining the Negative Returns to VIX Futures and ETNs: An Equilibrium Approach," Working Paper Wisconsin School of Business.

Frank, M., 1979, "On the Simultaneous Associativity of $F(x, y)$ and $x+y F(x, y)$," Aequationes Math, 19, 194-226.

Fuertes, C., and A. Papanicolaou, 2014, "Implied Filtering Densities on the Hidden State of Stochastic Volatility," Applied Mathematical Finance, 21(6), 483-522.

Heston, S. L., 1993, "A Closed-Form Solution for Options with Stochastic Volatility with Applications to Bond and Currency Options," Review of Financial Studies, 6(2), 327-343.

Jackwerth, J., 2004, "Option-Implied Risk-Neutral Distributions and Risk Aversion," Research Foundation of AIMR, CFA Institute.

Jiang, G. J., and Y. S. Tian, 2005, "The Model-Free Implied Volatility and Its Information Content," Review of Financial Studies, 18(4), 1305-1342.

Kalnina, I., and D. Xiu, 2015, "Nonparametric Estimation of the Leverage Effect using Information from Derivatives Markets," Working Paper University of Chicago Booth School of Business.

McNeil, A. J., R. Frey, and P. Embrechts, 2005, Quantitative Risk Management: Concepts, Techniques and Tools. Princeton University Press. 
Mencía, J., and E. Sentana, 2013, "Valuation of VIX derivatives," Journal of Financial Economics, 108(2), 367-391.

Newey, W. K., and K. D. West, 1987, "A Simple, Positive-semidefinite, Heteroskedasticity and Autocorrelation Consistent Covariance Matrix," Econometrica, 55(3), 703-708.

Peacock, J. A., 1983, "Two-dimensional Goodness-of-fit Testing in Astronomy," Monthly Notices Royal Astronomy Society, 202, 615-627.

Song, Z., and D. Xiu, 2015, "A Tale of Two Option Markets: State-Price Densities and Volatility Risk," Journal of Econometrics, forthcoming.

Todorov, V., and G. Tauchen, 2011, "Volatility Jumps," Journal of Business \& Economic Statistics, 29(3), 356-371.

Trivedi, P., and D. Zimmer, 2007, Copula Modeling: An Introduction for Practitioners, vol. 1 of Foundations and trends in econometrics. Now Publishers Inc.

Whaley, R. E., 2014, "Trading Volatility: At What Cost?," The Journal of Portfolio Management, 40(1), 95-108.

White, H., 1980, "A Heteroskedasticity-Consistent Covariance Matrix Estimator and a Direct Test for Heteroskedasticity," Econometrica, 48(4), 817-838.

Zhang, L., 2011, "Estimating Covariation: Epps Effect, Microstructure Noise," Journal of Econometrics, 160(1), 33-47.

Zhang, L., P. A. Mykland, and Y. Ait-Sahalia, 2005, "A Tale of Two Time Scales: Determining Integrated Volatility With Noisy High-Frequency Data," Journal of the American Statistical Association, 100, 1394-1411. 


\section{A Technical Appendix}

This section provides necessary technical details for the simulation-based calibration of the index-to-volatility implied correlation.

\section{A.1 Modeling dependency between market return and volatility}

We first detail how we select the copula used in the main part and then explain our realized correlation computation.

\section{A.1.1 Copula selection procedures}

According to the Sklar's (1959) Theorem, every multivariate cumulative distribution can be represented as a copula function, defined over the marginal distributions, so that if we have a joint distribution $F$ with marginals $F_{1}, . ., F_{d}$, there exists a copula $C:[0,1]^{d} \rightarrow[0,1]$ such that for all $x_{1}, . ., x_{d} \in \mathbb{R}::^{29}$

$$
F\left(x_{1}, . ., x_{d}\right)=C\left(F_{1}\left(x_{1}\right), . ., F_{d}\left(x_{d}\right)\right)
$$

Empirically we test five different copula functions: two implicit ones (Gaussian and Student's t) and three explicit ones (Frank, Clayton, and Gumbel). The description and exact form of each copula can be found in McNeil, Frey, and Embrechts (2005), Trivedi and Zimmer (2007), and other sources; we provide the form of three of them (Frank, Student's t, and Gaussian) for completeness - these copulas work well for modeling asymmetric volatility risk.

For the two-dimensional case, denote by $u^{1}$ and $u^{2}$ random vectors with uniformly distributed marginals, where each realization of the random vector can be converted into the realization of the respective variable by using the inverse cumulative marginal distribution. The Frank (1979) copula is given by:

$$
C_{\theta}\left(u^{1}, u^{2}\right)=-\frac{1}{\theta} \log \left(1+\frac{\left.\left(\exp \left(-\theta u^{1}\right)-1\right)\left(\exp \left(-\theta u^{2}\right)\right)-1\right)}{\exp (-\theta)-1}\right) .
$$

where $\theta$ is the dependence parameter.

The Gaussian copula for a given correlation matrix $R$ can be written as

$$
C_{R}\left(u_{1}, u_{2}\right)=\Phi_{R}\left(\Phi^{-1}\left(u_{1}\right), \Phi^{-1}\left(u_{2}\right)\right),
$$

where $\Phi^{-1}$ is the inverse cumulative distribution function of a standard normal and $\Phi_{R}$ is the joint cumulative distribution function of a multivariate normal distribution with mean vector zero and covariance matrix equal to the correlation matrix $R$.

\footnotetext{
${ }^{29}$ For example, see page 186 of McNeil, Frey, and Embrechts (2005).
} 
The Student's t copula for a given correlation matrix $R$ and degrees of freedom $\nu$ can be written as

$$
C_{R, \nu}\left(u_{1}, u_{2}\right)=t_{R, \nu}\left(t_{\nu}^{-1}\left(u_{1}\right), t_{\nu}^{-1}\left(u_{2}\right)\right),
$$

where $t_{\nu}^{-1}$ is the inverse cumulative distribution function of a t distribution with $\nu$ degrees of freedom and $t_{R, \nu}$ is the joint cumulative distribution function of a multivariate $\mathrm{t}$ distribution with mean vector zero, covariance matrix equal to the correlation matrix $R$, and $\nu$ degrees of freedom.

In order to calibrate a copula under the actual probability measure, we first create the time series $r(\tau)$ of $\log$ returns of S\&P 500 futures and $r^{V I X}(\tau)$ of $\log$ changes in VIX levels over a month $(\approx 20$ trading days), where we sample these variables three times per day (morning, mid-day, and evening) to mitigate possible biases from using only end-of-day closing levels: ${ }^{30}$

$$
\left[\begin{array}{c}
r(\tau) \\
r^{V I X}(\tau)
\end{array}\right] \equiv \log \left[\begin{array}{c}
P(\tau) \\
P^{V I X}(\tau)
\end{array}\right]-\log \left[\begin{array}{c}
P\left(\tau^{-}\right) \\
P^{V I X}\left(\tau^{-}\right)
\end{array}\right]
$$

where $P$ and $P^{V I X}$ are the levels of S\&P 500 futures and VIX, respectively, $\tau$ is the observation time point, and there is a 20-trading-days interval between the previous $\tau^{-}$and the current $\tau$ price points. For each of the series, we use kernel smoothing based on a normal kernel function with optimal bandwidth (Bowman and Azzalini (1997)) to estimate the cumulative density function and then estimate the respective copula parameters using maximum likelihood. ${ }^{31}$ This gives us the unconditional dependency parameter for each copula $\theta$, and for the $t$ copula also the degrees of freedom parameter $\nu$. To test how well the dependency in real data is captured by each copula, we simulate a large number of realizations from each copula and use the 2dimensional Kolmogorov-Smirnov test developed in Peacock (1983) to test the null that the simulated distribution is the same as the empirical one.

The calibrated parameters of the copulas under the actual probability measure and the results of the tests are provided in Table A1, Panel A; moreover, in Figure A1 we depict the empirical versus the simulated joint distributions of realizations of the market index returns and VIX. Visually the empirical distribution are well be represented by three copulas - Frank, Student's t, and Gaussian, while the Clayton and Gumbel copulas do not fit the data as well. Our visual evidence is confirmed by the p-values of the 2-dimensional Kolmogorov-Smirnov test, which are similarly large for the first three copulas (0.2452, 0.1987, and 0.1821, respectively), and as a result, we fail to reject for them the null about similarity of the empirical and simulated joint distributions. The empirical unconditional correlation is -0.7356 , and both Student's t

\footnotetext{
${ }^{30}$ Note that, even though the changes are both computed from $\tau^{-}$to $\tau$, the return is backward-looking while the expected volatility is forward-looking.

${ }^{31}$ For the Gumbel copula we use the series of index return and the series of minus changes in VIX, because this copula is used to model positive dependency, and the expected direction of dependency in our case is negative.
} 
Table A1: Copula calibrations

The table shows calibrated Frank, Student's t, Gaussian, Clayton, Gumbel copulas describing unconditional actual dependency between market index return and future expected volatility (Panel $A$ ) and average conditional risk-neutral dependency between market index and future expected volatility(Panel B). Panel $A$ is based on monthly log S\&P 500 returns and log-changes in VIX (equation (A5)) for the whole sample period. The Copula parameters column shows the single dependency parameter for all copulas and two parameters (correlation and degrees of freedom) for Student's t copula. The Correlation column contains the realized correlation of the empirical distribution and the simulated correlation for each model. $K S$ test gives the p-value of the two-sided 2-dimensional Komogorov-Smirnov test with the null hypothesis $H_{0}$ that the given simulated distribution is indistinguishable from the empirical one. The last column indicates if we reject the null. Panel B gives the average (across all observation dates) values of Copula parameters, the average Correlation from the simulated distributions, the standard errors in Correlation SE, and Pricing Errors computed as the root mean squared relative difference between implied volatility from the observed and modeled option prices.

Panel A: Unconditional calibration under the actual $(P)$ measure

\begin{tabular}{lcccc} 
Model & Copula parameters & Correlation & KS test (p-value) & Reject $H_{0}$ \\
\hline Empirical distribution & - & -0.7358 & - & - \\
Frank & -7.0306 & -0.6475 & 0.2452 & fail to reject \\
Student's t & $-0.7642 / 12.56$ & -0.7516 & 0.1987 & fail to reject \\
Gaussian & -0.7551 & -0.7395 & 0.1821 & fail to reject \\
Clayton & 0.0000 & -0.0201 & 0.0000 & reject \\
Gumbel & 2.0567 & -0.6326 & 0.0089 & reject \\
\hline
\end{tabular}

Panel B: Average conditional calibration under the risk-neutral $(Q)$ measure

\begin{tabular}{lcccc} 
Model & Copula parameters & Correlation & Correlation SE & Pricing Errors \\
\hline Frank & -70.1377 & -0.8104 & 0.0080 & 0.0316 \\
Student's t & $-0.8789 / 12.56$ & -0.8469 & 0.0081 & 0.0321 \\
Gaussian & -0.8700 & -0.8304 & 0.0080 & 0.0350 \\
Clayton & 17.0499 & -0.9418 & 0.0045 & 0.0328 \\
Gumbel & 0.6909 & -0.0796 & 0.0110 & 0.0658 \\
\hline
\end{tabular}

and the Gaussian copula produce similar correlations (-0.7516 and -0.7395, respectively), while the correlation from the Frank copula underestimates the magnitude relative to the empirical counterpart and is only $-0.6475 .^{32}$

We also calibrate all copulas under the risk-neutral probability measure, as described in Appendix subsection A.5. The results of this calibration are provided in Panel B of Table A1. Looking at column Pricing Errors, defined as the average relative deviation of model-based implied volatilities from observed ones, we see that the Frank copula delivers the lowest pricing error among all copulas, which is on average $3.16 \%$; the complete distribution of these errors can be seen in Figure A2.

\footnotetext{
${ }^{32}$ We also use pairwise tests for the differences among distributions using the same 2-dimensional KolmogorovSmirnov test. The Frank, the Gaussian and Student's t copula produce statistically indistinguishable joint distributions, while we reject the null for all pairs if the joint distributions involve either the Clayton or the Gumbel copulas.
} 
Figure A1: Joint distribution under physical measure: copula selection

We depict in six panels below the scatter plots representing the joint distribution between S\&P 500 monthly log returns and log changes in VIX over the corresponding period; the first plot comes from the empirical distribution, and the others are simulated from a particular copula function, calibrated to the empirical data. Please refer to Section 4.1 for details on computation.
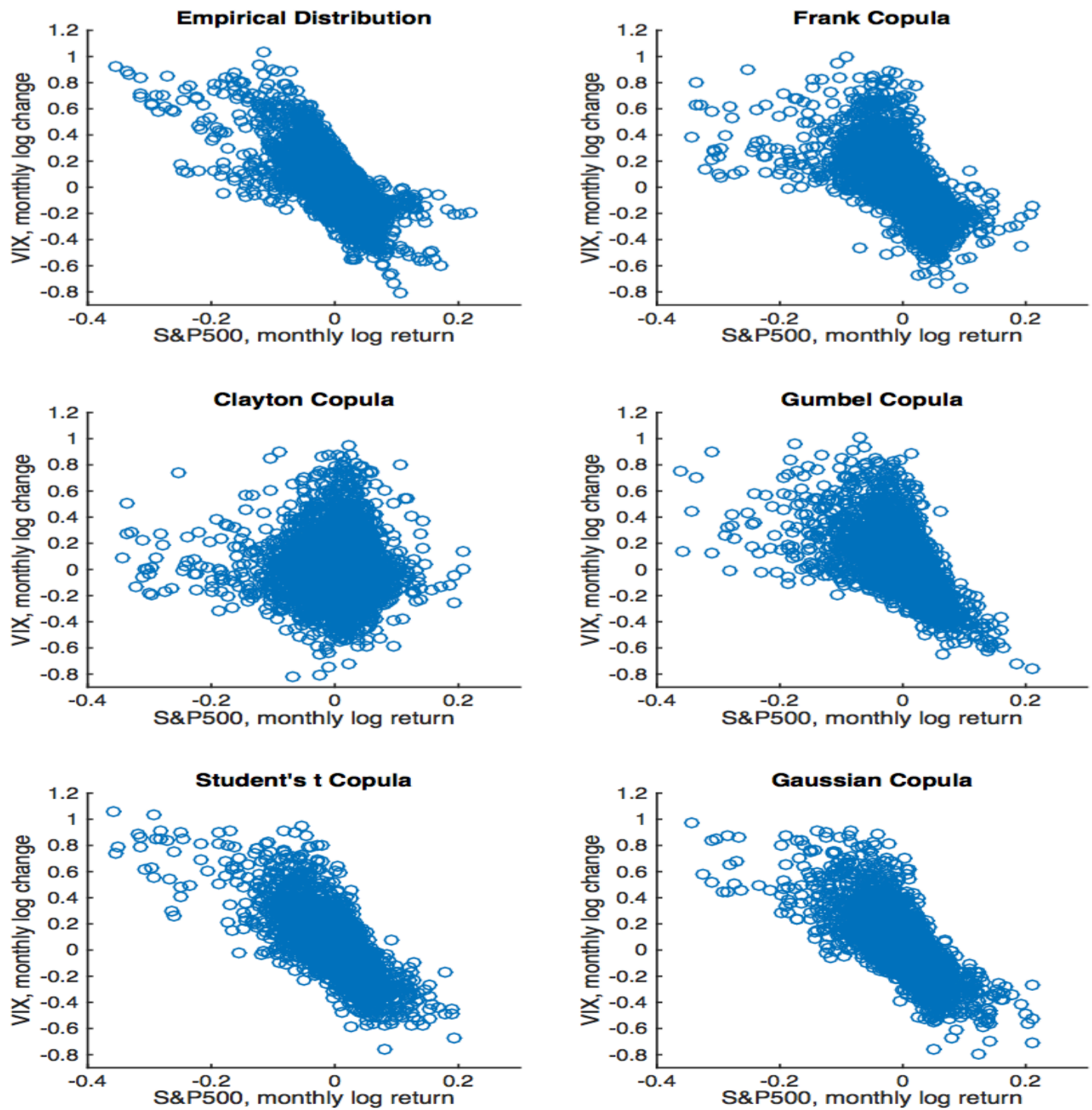
Figure A2: Distribution of the pricing errors for long-term options

For the sample from July 2007 until August 2014 (345 weekly observations), we show the histogram of the root mean squared pricing errors for long term options defined as the relative deviation of modelbased implied volatility from the observed implied volatility for the available long-term options. We use the Frank (1979) copula for calibration.

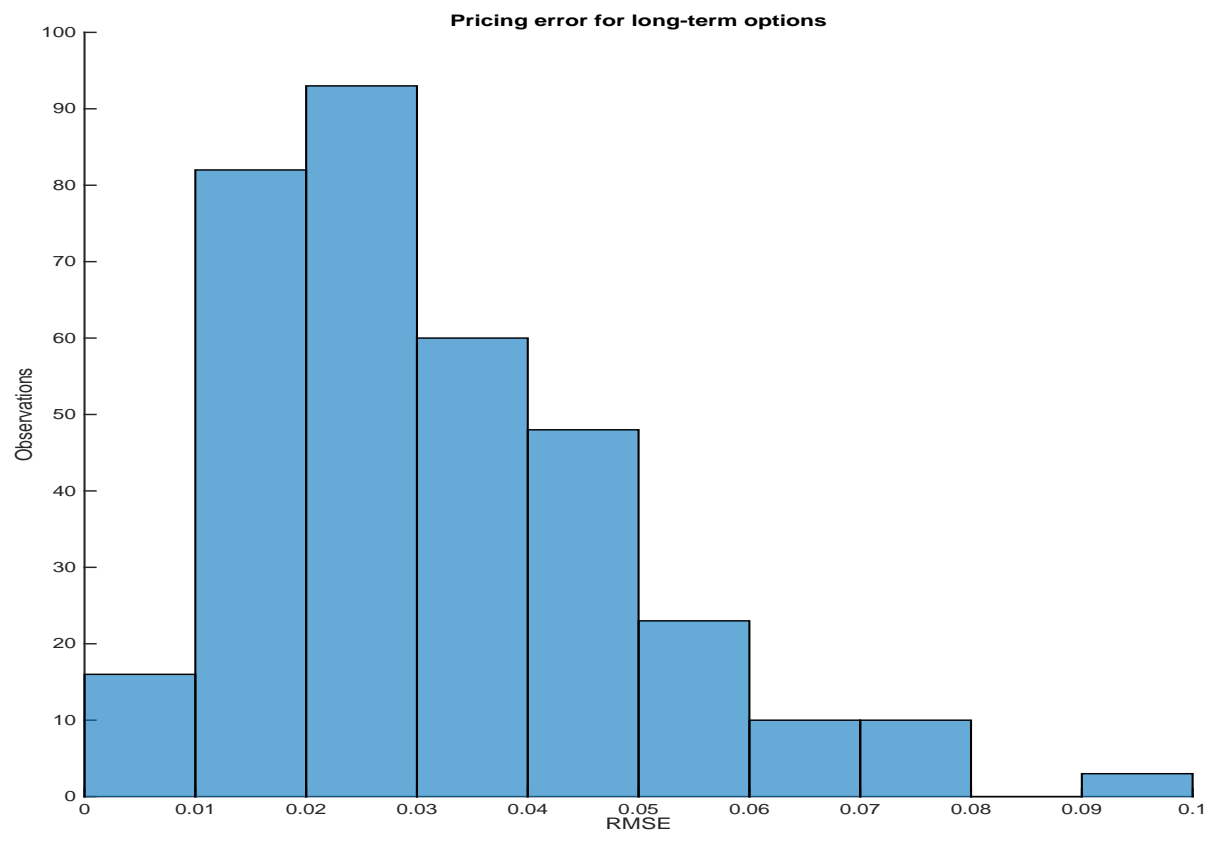




\section{A.1.2 Computing correlation between market return and volatility}

Ideally, we would like to compute realized correlations based on monthly returns and changes in expected volatility, as in equation (A5). However, since we want to obtain conditional results at our observation dates, we need to resort to high-frequency data over shorter returns and expected volatilities. We use the second-best method (resampling and averaging) of Zhang, Mykland, and Ait-Sahalia (2005) and we estimate the realized covariance from time $t^{-}$up to $t$ by the matrix $\Sigma\left(t^{-}, t\right)$ :

$$
\Sigma\left(t^{-}, t\right)=\sum_{k=1}^{S}\left[\begin{array}{c}
r\left(t^{-}+k \delta\right) \\
r^{V I X}\left(t^{-}+k \delta\right)
\end{array}\right] \times\left[\begin{array}{ll}
r\left(t^{-}+k \delta\right) & r^{V I X}\left(t^{-}+k \delta\right)
\end{array}\right]
$$

where $S$ denotes the number of sampling periods, $\delta \equiv\left(t^{-}-t\right) / S$ is the sampling frequency, and

$$
\left[\begin{array}{c}
r\left(t^{-}+k \delta\right) \\
r^{V I X}\left(t^{-}+k \delta\right)
\end{array}\right] \equiv \log \left[\begin{array}{c}
P\left(t^{-}+k \delta\right) \\
P^{V I X}\left(t^{-}+k \delta\right)
\end{array}\right]-\log \left[\begin{array}{c}
P\left(t^{-}+(k-1) \delta\right) \\
P^{V I X}\left(t^{-}+(k-1) \delta\right)
\end{array}\right]
$$

is the vector of log-changes in the S\&P 500 index futures and VIX levels. Our data is available at the minute level but, in order to avoid microstructural (i.e., Epps (1979) effect) problems, we use $\delta=30,60,90$, and 120 minutes. Next, we compute the covariance estimator (A6) for each choice of $\delta$, where we use the overlapping data series starting at each minute, and we take the average of the resulting four estimators as our final covariance matrix $\Sigma^{\bar{\delta}}\left(t^{-}, t\right)$. The diagonal elements of the covariance matrix are the variances of the respective variables, and the realized correlation $\left(R C_{t^{-}, t}\right)$ is given by an off-diagonal element of the matrix

$$
\Theta=\operatorname{diag}\left(\Sigma^{\bar{\delta}}\left(t^{-}, t\right)\right)^{-1 / 2} \times \Sigma^{\bar{\delta}}\left(t^{-}, t\right) \times \operatorname{diag}\left(\Sigma^{\bar{\delta}}\left(t^{-}, t\right)\right)^{-1 / 2} .
$$

Why and when can we estimate the correlation of the monthly return-to-volatility realizations (defined in equation (A5) and used for the copula calibration, we have monthly returns and changes in expected volatility observed three times a day during the whole sample) by the correlations of the high-frequency realizations (an average of returns and changes in expected volatility over 30, 60, 90, and 120 minutes observed every minute during one month)? The theoretical justification for using high-frequency data on the market index and an integrated volatility proxy (like VIX) is given by Kalnina and Xiu (2015), who define "spot leverage," corresponding to our realized correlation $R C_{t^{-}, t}$ from equation (A8), and "integrated leverage," computed as the time-series average of the realized correlation. The latter corresponds to an unconditional expectation of our realized index-to-volatility correlation. Andersen, Bondarenko, and Gonzalez-Perez (2015) provide an empirical rationale for different realized correlation estimators and find that one should not sample processes too frequently in order to capture joint jumps for a correct "leverage effect" estimation.

While there is no theoretical procedure (except for signature plots) for selecting the optimal sampling frequency, we treat it as an empirical question and contrast the correlations computed 
from monthly (defined in equation (A5) and used for the copula calibration) and from highfrequency increments of market index and future expected volatility (VIX). The estimator based on monthly increments is -0.7356 and the other, based on our high-frequency increments, is -0.7358 ; i.e., they are almost identical (and not significantly different at 0.01 level). Thus, we can confirm that our high-frequency estimator is a suitable proxy for the realized index-tovolatility correlation.

\section{A.2 Preparation of data for S\&P 500 and VIX options}

1. We create a sample with observations recorded on a weekly basis and proceed as follows. For each month in our sample we find the expiration dates of three sets of optionsVIX options (expiring on the Wednesday that is thirty days prior to the third Friday of the calendar month immediately following the expiring month), short-term S\&P 500 options expiring on the third Saturday immediately following the third Friday of the expiration month, and long-term S\&P 500 options expiring on the third Saturday of the next month. ${ }^{33}$ Then, we take the expiration date of the short-term S\&P 500 options and create four observation dates by going backwards four times by one week, so that each date is a trading day being at least 7 days earlier than the next date, and earlier than the VIX expiration date in a given month. The earliest observation date generated from a given month S\&P 500 expiration should be at least 5 days later than the last observation data generated from an earlier month.

2. Process OptionMetrics data using raw options for S\&P 500 and VIX. Raw data includes underlying spot price, bid/ask prices of options, mid-point implied volatility, date of observation, and days to maturity.

3. Recompute implied volatilities (IVs) for VIX options. The OptionMetrics database (version update on WRDS from December 2014) contains an error in computing implied volatility of the VIX options - instead of using the futures level, OptionMetrics uses the current VIX level as the at-the-money reference level without using the correct cost of carry/convenience yield. Instead of using cost of carry/convenience yield in the BlackScholes formula, one can use the futures level directly and infer the implied volatility by inverting the Black (1976) formula.

\footnotetext{
${ }^{33}$ This expiration rule holds for SPX options until February 15, 2015, i.e., for all of our sample length. On and after February 15, 2015, the expiration date will be the third Friday of the expiration month.
} 
We merge options data with end-of-day data on futures (from CBOE) and compute the implied volatilities by inverting the Black formula:

$$
\begin{aligned}
\operatorname{Call}(T, F, K) & =e^{-r T}\left[F \times N\left(d_{1}\right)-K \times N\left(d_{2}\right)\right], \\
\operatorname{Put}(T, F, K) & =e^{-r T}\left[K \times N\left(-d_{2}\right)-F \times N\left(-d_{1}\right)\right], \\
d_{1} & =\frac{\log (F / K)+\left(\sigma^{2} / 2\right) T}{\sigma \sqrt{T}}, d_{2}=d_{1}-\sigma \sqrt{T},
\end{aligned}
$$

where $T$ is the time to maturity, $F$ is the futures level, $K$ is the strike, $r$ is the prevailing risk-free rate, $N(\cdot)$ is the cumulative standard normal distribution function, and $\sigma$ is the implied volatility we are looking for.

4. For each observation date, record the S\&P 500 continuous dividend yield $\delta_{t}$ and interpolate the zero CD rate (from OptionMetrics) for the exact days-to-maturity of the short-term and long-term S\&P 500 options to find the continuously compounded rate $r_{f, t}$ for a given observation date.

5. Filter the short-term options for calibration on a given observation date. For S\&P 500 use out-of-the-money (OTM) calls and puts with moneyness (defined as $K / S$ with respect to the current S\&P 500 level $S$ ) between 0.7 and 1.3, i.e., filter out puts with $K / S>1$ and calls with $K / S<1$, and for both types of options filter out $K / S<0.7$ and $K / S>1.3 .^{34}$ For VIX use all OTM calls and puts, where moneyness is determined with respect to the futures level (i.e., moneyness is $K / F$ ). We limit moneyness to the range from 0.2 to 3.0. For both underlying securities we normalize option strike by the underlying price (i.e., spot price for S\&P 500 and futures level for VIX), so that each option strike now represents the gross return (or relative change) for the given underlying security on the maturity date. We estimate the marginal risk-neutral density from S\&P 500 and VIX options for the dates, where we have at least 8 and 5 available options, respectively.

\section{A.3 Estimation of the risk-neutral distribution for the market index}

We estimate marginal risk-neutral distributions (RNDs) for S\&P 500 from observed short-term options using the "fast and stable method" of Jackwerth (2004). The method finds a smooth risk-neutral distribution that, at the same time, explains the option prices. ${ }^{35}$

1. Fit the implied volatility curve as a function of the moneyness with values $\sigma_{j}$ at discrete moneyness grid points $\left(1+r_{j}\right) \in[0.5,1.5], j=1 \ldots N$. To fit the implied volatility function we select the spacing of the moneyness grid $\Delta$ and the smoothness parameter $\lambda$.

\footnotetext{
${ }^{34}$ In robustness test we also apply different filters on the moneyness of options with minor changes to the results.

${ }^{35}$ See Appendix A in Jackwerth (2004) for technical details.
} 
Because the "fast and stable method" leads to a system of equations, where coefficients are functions of the step size of the moneyness grid, and because S\&P 500 options are too close to each other in moneyness, there is not enough machine accuracy to solve the system. To circumvent the problem, we multiply all moneyness points by 1000 and divide by the same multiplier when we need raw returns. Output from the procedure is a grid of raw returns (i.e., moneyness points) $1+r_{j}$ between 0.5 and 1.5 , with respective implied volatilities $\sigma_{j}$ for all points on the grid. The risk-neutral probabilities of return $\hat{Q}\left(r_{j}\right)$ can be written directly as

$$
\begin{aligned}
\hat{Q}\left(r_{j}\right) & =e^{r T}\left[\frac{e^{-r T} n\left(d 2_{j}\right)}{\left(1+r_{j}\right) \sigma_{j} \sqrt{T}}\left(1+2\left(1+r_{j}\right) d 1_{j} \sigma_{j}^{\prime} \sqrt{T}\right)+e^{-\delta T} n\left(d 1_{j}\right) \sqrt{T}\left(\sigma_{j}^{\prime \prime}+\frac{d 1_{j} d 2_{j}}{\sigma_{j}}\left(\sigma_{j}^{\prime}\right)^{2}\right)\right] \\
d 1_{j} & =\frac{-\log \left(\left(1+r_{j}\right)\right)+(r-\delta) T+\left(\sigma_{j}^{2} / 2\right) T}{\sigma_{j} \sqrt{T}}, d 2_{j}=d 1_{j}-\sigma_{j} \sqrt{T}
\end{aligned}
$$

where $T$ is the time to maturity, $r_{j}$ is the moneyness level at grid point $j, r$ is the prevailing risk-free rate, $\delta$ is the dividend yield, $\sigma_{j}$ is the implied volatility at the grid point $j, \sigma_{j}^{\prime}$ and $\sigma_{j}^{\prime \prime}$ are the first and second derivatives of the volatility function with respect to moneyness at grid point $j$, and $n(\cdot)$ is the standard normal density function.

2. Due to requirements on the smoothness of the resulting risk-neutral distribution, the model implied volatilities do not exactly fit the observed implied volatilities. To improve the fit of the risk-neutral distribution to the observed option prices, while maintaining its smoothness controlled directly by the parameters of the fast and stable method, we introduce the second step in the RND estimation. After deriving numerically the "fast and stable" RND of index returns $\hat{Q}\left(r_{j}\right)$, we explicitly set its mean to the risk-free rate minus the dividend rate $\left(\left(r_{f}-\delta\right) \times T\right)$, which is the proper drift of the traded asset under the risk-neutral probability measure, and we also adjust the variance of the distribution to $\left(\hat{\sigma}_{\text {opt }}\right)^{2} \times T$, so that we achieve the best fit of the option prices computed from the derived RND to the observed options prices.

The final distribution fits the option prices with the least error. We normalize that distribution to have unit annual variance and drift equal to the risk-free rate minus dividend per annum, i.e., we change the support (all realizations $j=1, \ldots, N$ ) of the distribution $\hat{Q}(\cdot)$ from $r_{j}$ to $m_{j}$ as follows:

$$
m_{j}=\frac{r_{j}-\left(r_{f}-\delta\right) \times T}{\hat{\sigma} \times \sqrt{T}}+r-\delta, \quad \forall j=1, \ldots, N
$$




\section{A.4 Estimation of the risk-neutral distribution for the future market volatil- ity}

We estimate marginal RND for future expected volatility from observed short-term VIX options using the "fast and stable method."

1. Fit the implied volatility curve as a function of the moneyness with values $\sigma_{j}$ at discrete moneyness grid points $m_{j}^{\sigma} \in[0.2,3.0], j=1 \ldots N$. We select the moneyness grid spacing $\Delta$ and the smoothness parameter $\lambda$. As is the case with the S\&P 500 options, we multiply all moneyness grid points by 1000 and divide by the same multiplier when we need raw returns. Output from the procedure is a grid of raw VIX changes (i.e., moneyness grid points) $m_{j}^{\sigma}$ between 0.2 and 3.0, with respective implied volatilities $\sigma_{j}$ for all points on the grid. The risk-neutral probability distribution $\hat{Q}^{\sigma}\left(m_{j}\right)$ can be written directly as a function of implied volatilities, option moneyness, and maturity, as shown for the case of $\mathrm{S} \& \mathrm{P} 500$ in equation (A12); note that because VIX is not traded, we set both the interest rate $r$ and the dividend yield $\delta$ to zero, using moneyness $m_{j}$ defined with respect to the VIX futures level.

2. Due to the requirements on the smoothness of the resulting risk-neutral distribution, the model implied volatilities do not exactly fit the observed implied volatilities of the VIX options. To improve the fit of the risk-neutral distribution to the observed option prices, while maintaining its smoothness controlled directly by the parameters of the fast and stable method, we introduce the second step in RND estimation, where we adjust the volatility of the distribution so that the model based VIX option prices (computed from the derived RND) best fit the observed options prices. As opposed to S\&P 500 RND estimation, where we apply two adjustments (to the mean and to the volatility), the drift of the risk-neutral distribution of VIX is not fixed at the level of risk-free rate minus dividends. Hence, we apply only the volatility adjustment; the mean of the VIX changes is just equal to one, because the changes are defined relative to the VIX futures level.

\section{A.5 Construction of a second-month and of a two-month risk-neutral distri- butions for the market}

We generate a two-period (corresponding to the maturity of the longer-term options on each calibration date) risk-neutral distribution of S\&P 500 returns.

1. On each observation date we are given: a short-term risk-neutral distribution $\hat{Q}$ for standardized S\&P 500 returns with support $m_{j}, j=1 \ldots N$, and a second-period risk-neutral distribution $\hat{Q}^{\sigma}$ for expected future volatility changes from its reference value with support $m_{j}^{\sigma}, j=1 \ldots N^{\sigma}$. We use each density function and the grid points from the respective 
supports to estimate the interpolated inverse cumulative distribution function Qinv and Qinv ${ }^{V I X}$, such that:

$$
\begin{gathered}
m=\operatorname{Qinv}\left(\int_{-\infty}^{m} \hat{Q}(m) d m\right), \\
m^{\sigma}=\operatorname{Qinv}^{\sigma}\left(\int_{-\infty}^{m^{\sigma}} \hat{Q}^{\sigma}(m) d m\right) .
\end{gathered}
$$

We generate 200,000 draws from a joint distribution of standardized market returns and deviation in future expected volatility, where the joint cumulative distribution function is defined by a copula. In the main analysis we use the Frank (1979) copula with the representation (A2), where $\theta$ is the dependence parameter and $u$ and $u^{\sigma}$ are random vectors with uniformly distributed marginals, where each realization of the random vector can be converted into the realizations of normalized returns and deviations from future expected volatility by applying transforms (A15) and (A16).

Thus, each draw is given by a pair of uniformly distributed numbers $u, u^{\sigma} \sim U[0,1]$, where $u$ is iid, and $u^{\sigma}$ is drawn conditionally on $u$ and the copula parameter $\theta$. The corresponding realizations of a market return and its future expected volatility are given by $m=\operatorname{Qinv}(u)$ and $m^{\sigma}=\operatorname{Qinv}^{\sigma}\left(u^{\sigma}\right)$, respectively. The risk-neutral joint cumulative distribution function for a given pair of realizations is given by the copula function:

$$
\hat{Q}\left(m, m^{\sigma}\right)=\hat{Q}\left(\operatorname{Qinv}(u), \operatorname{Qinv}^{\sigma}\left(u^{\sigma}\right)\right)=C_{\theta}\left(u, u^{\sigma}\right) .
$$

2. For each pairwise realization $i=1, \ldots, 200,000$ of the standardized market return $m_{i}$ and the change in expected volatility $m_{i}^{\sigma}$, construct the conditional second-period distribution of market returns, such that its volatility is equal to the drawn realization of the relative change in future expected volatility multiplied by the expected volatility $E\left[\sigma_{1}\right]$, and the mean is equal to the risk-free rate minus dividend, adjusted appropriately for the period length. ${ }^{36}$

The distribution will have the same probabilities $\hat{Q}_{j}$ of each realization of a return for a grid point $j$ as in the first month, but the grid point value will change from $m_{j}$ to $r_{j, 2}$ to

\footnotetext{
${ }^{36}$ The distribution of deviations of future volatility from the mean of one can be changed to the distribution of the expected future volatilities for the period from $t 1$ to $t 2$ by multiplying all points in its domain by the expected volatility $\bar{\sigma}_{t 1, t 2}$ :

$$
\sigma_{t 1, t 2}=m^{\sigma} \times \bar{\sigma}_{t 1, t 2} \sim \hat{Q}_{t}^{\sigma} \text { with mean } \bar{\sigma}_{t 1, t 2} .
$$

The distribution of normalized market returns can be easily turned into a distribution of market returns $r_{t 1, t 2}$ with a specified volatility $\sigma_{t 1, t 2}$ for a given period of time from $t 1$ to $t 2$ by changing the discrete points of the distribution support by demeaning them, adjusting volatility, and then adding back the mean for the required
} period length $t 2-t 1$ :

$$
r_{t 1, t 2}=\left(m-\left(r_{f}-\delta\right)\right) \sigma_{t 1, t 2} \sqrt{t 2-t 1}+\left(r_{f}-\delta\right)(t 2-t 1) \sim \hat{Q}_{t 1}\left(\left(r_{f}-\delta\right)(t 2-t 1), \sigma_{t 1, t 2}^{2}\right) .
$$


reflect the volatility realization drawn for this run. At this point we have 200, 000 secondperiod distributions, each generated by a draw of first-period return and second-period expected volatility.

3. Next, we construct 200,000 two-period distributions of market returns. The support of each two-period distribution, conditional on the draw $\left\{m_{i}, m_{i}^{\sigma}\right\}$, is given by the product of the first-period draw of the return realization $1+r_{i}$ and each adjusted realization of second-period market return, $1+r_{j, 2}$ :

$$
r_{j, i, 2}=\left(1+r_{i}\right) \times\left(1+r_{j, 2}\right)-1, \forall j=1, \ldots, N
$$

In other words, the two-period distribution is computed as follows:

$$
\begin{aligned}
\hat{Q}_{t}\left(r_{t, t 2}\right) & =\hat{Q}_{t}\left(r_{t, t 1}, r_{t 1, t 2}\right) \\
& =\sum_{\sigma_{t 1, t 2}} \hat{Q}_{t}\left(r_{t 1, t 2}, r_{t, t 1}, \sigma_{t 1, t 2}\right) \\
& =\sum_{\sigma_{t 1, t 2}} \hat{Q}_{t}\left(r_{t 1, t 2} \mid r_{t, t 1}, \sigma_{t 1, t 2}\right) \times \hat{Q}_{t}\left(r_{t, t 1}, \sigma_{t 1, t 2}\right) .
\end{aligned}
$$

We can now directly use the 200,000 resulting conditional two-period distributions in a Monte-Carlo procedure to price the two-period (long-term) options on the market index. Since we are also interested in the properties of the unconditional two-period distribution, we collect all realizations of the conditional two-period distributions $r_{j, i, 2}, \forall j=1, \ldots, N$, $i=1, \ldots, 200,000$, and allocate them to 500 equally spaced bins; from the allocated realizations compute the average realization in each bin, and allocate to this return realization a probability $\hat{Q}_{2, j}$ equal to the sum of the product of the probability of the two-period conditional return ending up in bin $j$ times the probability of draw $j$ occurring.

4. Use the two-period market return distribution to price two-period (long-term) market index options: compute the payoff for an option with a given strike price and maturity for each of the 500 grid points, compute the expectation of the payoff (we use normalized payoff here to avoid dealing with different price levels on each date) using the adjusted $\mathrm{RND}$, and discount at the risk-free rate:

$$
\begin{aligned}
& \operatorname{Prc}_{c}^{e s t}=e^{-r T_{2}} \sum_{z=1}^{500} \hat{Q}_{2}\left(r_{2, z}\right) \times\left(\left(r_{2, z}+1\right)-\frac{K_{c}}{S}\right)^{+}, \forall c \in\{\text { Observed Calls }\}, \\
& \operatorname{Prc}_{p}^{e s t}=e^{-r T_{2}} \sum_{z=1}^{500} \hat{Q}_{2}\left(r_{2, z}\right) \times\left(\frac{K_{p}}{S}-\left(r_{2, z}+1\right)\right)^{+}, \forall p \in\{\text { Observed Puts }\} .
\end{aligned}
$$

5. Invert the Black and Scholes (1973) option pricing formula to get the implied volatilities from the observed two-period option prices $I V^{o b s}$ and from the option prices for the 
same strikes estimated in equations (A22) and (A23), i.e., $I V^{\text {est }}$. Calibrate the copula parameter $\theta$ and future expected volatility level $E\left[\sigma_{1}\right]$ to minimize the pricing error in terms of implied volatilities in two-month market index options (we minimize the RMSE of $I V^{e s t}$ relative to the observed $I V^{e s t}$ for all available out-of-the-money options within the moneyness range of $[0.8,1.2])$ :

$$
\left\{\theta, E\left[\sigma_{1}\right]\right\}=\arg \min \sqrt{\frac{1}{\# j \in\{c, p\}} \sum_{j \in\{c, p\}}\left(\frac{I V_{j}^{\text {est }}}{I V_{j}^{\text {obs }}}-1\right)^{2}} .
$$

Estimate the index-to-volatility correlation directly from the 200,000 draws of pairwise realizations of market return and changes in volatility. 


\section{Internet Appendix: Tables and Figures for Robustness Tests}

Table IA1: Predicting second-period S\&P 500 performance for other copulas

We define our dependent variables as second-period realized return and volatility, measured from the expiry of the nearest maturity options until the expiry of the longer-term options. Realized volatility is computed from high-frequency returns. Independent variables are the index-to-volatility implied correlation, VIX, the variance risk premium, and the difference between long-and short-term implied skewness. In Panel A the index-to-volatility correlation is based on the Student's t copula, and in Panel B - on the Gaussian copula. The p-values are based on the Newey and West (1987) standard errors with four lags.

\begin{tabular}{l|ccc|ccc} 
Panel A: Student's t copula & \multicolumn{3}{c}{ Return } & \multicolumn{3}{c}{ Volatility } \\
\hline & $(1)$ & $(2)$ & $(3)$ & $(4)$ & $(5)$ & $(6)$ \\
Intercept & 0.685 & 0.793 & 0.860 & 0.017 & 0.000 & 0.064 \\
p-val & 0.000 & 0.000 & 0.000 & 0.981 & 0.009 & 0.026 \\
Implied Correlation & 0.738 & 1.000 & 0.877 & -0.191 & -0.061 & -0.159 \\
p-val & 0.000 & 0.000 & 0.000 & 0.000 & 0.070 & 0.000 \\
VIX & - & 0.715 & - & - & 0.569 & - \\
p-val & - & 0.284 & - & - & 0.000 & - \\
Variance Risk Premium & - & - & 0.508 & - & - & -0.328 \\
p-val & - & - & 0.403 & - & - & 0.543 \\
Implied Skewness, long-short & - & -0.135 & -0.184 & - & -0.002 & -0.044 \\
p-val & - & 0.137 & 0.014 & - & 0.404 & 0.000 \\
\hline Adjusted $R^{2}$ & $2.6 \%$ & $4.8 \%$ & $3.7 \%$ & $6.2 \%$ & $31.3 \%$ & $9.4 \%$
\end{tabular}

Panel B: Gaussian copula

\begin{tabular}{l|ccc|ccc} 
& \multicolumn{3}{|c|}{ Return } & \multicolumn{3}{c}{ Volatility } \\
\hline & $(1)$ & $(2)$ & $(3)$ & $(4)$ & $(5)$ & $(6)$ \\
Intercept & 0.704 & 0.840 & 0.906 & 0.004 & -0.009 & 0.050 \\
p-val & 0.000 & 0.000 & 0.000 & 0.237 & 0.583 & 0.142 \\
Implied Correlation & 0.775 & 1.085 & 0.944 & -0.211 & -0.073 & -0.178 \\
p-val & 0.000 & 0.000 & 0.000 & 0.000 & 0.057 & 0.000 \\
VIX & - & 0.765 & - & - & 0.563 & - \\
p-val & - & 0.243 & - & - & 0.000 & - \\
Variance Risk Premium & - & - & 0.539 & - & - & -0.334 \\
p-val & - & - & 0.415 & - & - & 0.504 \\
Implied Skewness, long-short & - & -0.147 & -0.198 & - & -0.001 & -0.040 \\
p-val & - & 0.093 & 0.008 & - & 0.221 & 0.000 \\
\hline Adjusted $R^{2}$ & $2.9 \%$ & $5.4 \%$ & $4.2 \%$ & $7.5 \%$ & $31.6 \%$ & $10.3 \%$
\end{tabular}


Table IA2: Predicting second period risk-neutral quantities for S\&P 500

We use as dependent variables the selected characteristics of the option-implied distribution of S\&P 500 estimated on the expiry date $t 1$ of the short-term options that are used to calibrate the index-tovolatility implied correlation at time $t$. The dependent variables are the "Right tail minus Left tail" variable computed as the probability mass to the right of the $10 \%$ monthly return minus the probability mass to the left of the $-10 \%$ monthly return (which corresponds approximately to the $\pm 2 \sigma$ event if unconditional market volatility is $17 \%$ p.a.) and implied skewness and volatility that are computed from the estimated risk-neutral density. Independent variables are the index-to-volatility implied correlation, VIX, the variance risk premium, and the difference between long-and short-term implied skewness. In Panel A the index-to-volatility correlation is based on the Student's t copula, and in Panel B - on the Gaussian copula. We use non-overlapping regressions to guarantee that the quantity we want to predict is always observed about one month after the estimation date $t$. For p-values we use White (1980) standard errors adjusted for heteroscedasticity.

Panel A: Student's t copula

\begin{tabular}{l|ccc|ccc|ccc} 
& \multicolumn{3}{|c|}{ Right } & minus & Left tail & \multicolumn{2}{c|}{ Implied skewness } & \multicolumn{2}{c}{ Implied volatility } \\
\hline & $(1)$ & $(2)$ & $(3)$ & $(4)$ & $(5)$ & $(6)$ & $(7)$ & $(8)$ & $(9)$ \\
Intercept & 0.040 & 0.021 & 0.031 & -3.102 & -2.827 & -2.505 & -0.002 & -0.015 & 0.013 \\
p-val & 0.346 & 0.864 & 0.546 & 0.000 & 0.000 & 0.000 & 0.099 & 0.921 & 0.541 \\
Implied Correlation & 0.099 & 0.106 & 0.093 & -1.980 & -1.252 & -1.573 & -0.088 & -0.045 & -0.076 \\
p-val & 0.022 & 0.007 & 0.030 & 0.012 & 0.154 & 0.106 & 0.180 & 0.344 & 0.244 \\
VIX & - & 0.074 & - & - & 2.374 & - & - & 0.208 & - \\
p-val & - & 0.002 & - & - & 0.000 & - & - & 0.000 & - \\
Variance Risk Premium & - & - & -0.056 & - & - & 2.999 & - & - & 0.143 \\
p-val & - & - & 0.912 & - & - & 0.265 & - & - & 0.473 \\
Implied Skewness, long-short & - & 0.027 & 0.017 & - & -0.922 & -1.212 & - & -0.005 & -0.031 \\
p-val & - & 0.001 & 0.058 & - & 0.000 & 0.000 & - & 0.996 & 0.004 \\
\hline Adjusted $R^{2}$ & $6.3 \%$ & $20.5 \%$ & $10.0 \%$ & $8.0 \%$ & $56.8 \%$ & $42.8 \%$ & $2.2 \%$ & $60.6 \%$ & $12.5 \%$
\end{tabular}

Panel B: Gaussian copula

\begin{tabular}{l|ccc|ccc|ccc} 
& \multicolumn{3}{|c|}{ Right } & minus & Left tail & \multicolumn{2}{c|}{ Implied skewness } & \multicolumn{3}{c}{ Implied volatility } \\
\hline & $(1)$ & $(2)$ & $(3)$ & $(4)$ & $(5)$ & $(6)$ & $(7)$ & $(8)$ & $(9)$ \\
Intercept & -0.008 & -0.031 & -0.023 & -3.153 & -2.275 & -2.009 & 0.014 & 0.018 & 0.041 \\
p-val & 0.921 & 0.097 & 0.312 & 0.000 & 0.000 & 0.000 & 0.810 & 0.399 & 0.094 \\
Implied Correlation & 0.063 & 0.064 & 0.068 & -1.892 & -0.474 & -0.804 & -0.061 & 0.0001 & -0.033 \\
p-val & 0.037 & 0.041 & 0.056 & 0.000 & 0.327 & 0.073 & 0.008 & 0.007 & 0.300 \\
VIX & - & 0.078 & - & - & 2.304 & - & - & 0.211 & - \\
p-val & - & 0.002 & - & - & 0.000 & - & - & 0.000 & - \\
Variance Risk Premium & - & - & -0.053 & - & - & 2.511 & - & - & 0.124 \\
p-val & - & - & 0.834 & - & - & 0.422 & - & - & 0.621 \\
Implied Skewness, long-short & - & 0.021 & 0.014 & - & -0.839 & -1.053 & - & -0.005 & -0.024 \\
p-val & - & 0.032 & 0.238 & - & 0.000 & 0.000 & - & 0.947 & 0.058 \\
\hline Adjusted $R^{2}$ & $3.6 \%$ & $15.6 \%$ & $4.4 \%$ & $20.7 \%$ & $56.2 \%$ & $43.3 \%$ & $8.2 \%$ & $59.7 \%$ & $12.2 \%$
\end{tabular}


Table IA3: Predicting second-period S\&P 500 performance with additional controls

We define our dependent variables as second-period realized return and volatility, measured from the expiry of the nearest maturity options until the expiry of the longer-term options. Realized volatility is computed from high-frequency returns. Independent variables are the index-to-volatility implied correlation (from the Frank copula), VIX, the variance risk premium, and the difference between longand short-term implied skewness, and four additional controls-Amihud Liquidity Measure, Momentum, Put-Call Open Interest Ratio, and Put-Call Volume Ratio. We estimate the Amihud (2002) liquidity measure using daily returns and volume information for the market exchange-traded fund for the S\&P500 index (SPY) on each observation day for the past month (previous 21 trading days). We use the data on all call and put options on the SPY to compute two proxies of market sentiment, namely the Put-Call Open Interest Ratio and the Put-Call Volume Ratio. On each observation date, we do so by recording the open interest (volume) of all put options on the SPY with maturity between eight days to one year and dividing it by the open interest (volume) of all call options with maturity during the same period. We also compute the Momentum sentiment measure as the current price deviation of the market index from the 125-day moving average price. The p-values are based on the Newey and West (1987) standard errors with four lags.

\begin{tabular}{l|ccc|ccc} 
& \multicolumn{3}{|c|}{ Return } & \multicolumn{3}{c}{ Volatility } \\
\hline & $(1)$ & $(2)$ & $(3)$ & $(4)$ & $(5)$ & $(6)$ \\
Intercept & -0.147 & -0.202 & -0.038 & 0.214 & 0.170 & 0.216 \\
p-val & 0.722 & 0.946 & 0.202 & 0.000 & 0.003 & 0.000 \\
Implied Correlation & 0.469 & 0.895 & 0.781 & -0.061 & -0.043 & -0.066 \\
p-val & 0.022 & 0.000 & 0.000 & 0.102 & 0.431 & 0.096 \\
VIX & - & 1.507 & - & - & 0.336 & - \\
p-val & - & 0.017 & - & - & 0.000 & - \\
Variance Risk Premium & - & - & 1.084 & - & - & -0.208 \\
p-val & - & - & 0.857 & - & - & 0.434 \\
Implied Skewness, long-short & - & -0.295 & -0.335 & - & 0.016 & 0.006 \\
p-val & - & 0.000 & 0.000 & - & 0.126 & 0.934 \\
Amihud Liquidity Measure & 0.874 & 0.876 & 1.121 & -0.078 & -0.127 & -0.090 \\
p-val & 0.002 & 0.001 & 0.000 & 0.088 & 0.001 & 0.057 \\
Momentum & 1.104 & 3.045 & 1.831 & -0.853 & -0.591 & -0.869 \\
p-val & 0.110 & 0.000 & 0.005 & 0.000 & 0.000 & 0.000 \\
Put-Call Open Interest Ratio & 0.128 & 0.164 & 0.166 & -0.008 & -0.012 & -0.007 \\
p-val & 0.472 & 0.210 & 0.216 & 0.830 & 0.797 & 0.717 \\
Put-Call Volume Ratio & -0.056 & -0.020 & -0.033 & -0.012 & -0.009 & -0.013 \\
p-val & 0.986 & 0.396 & 0.632 & 0.609 & 0.847 & 0.568 \\
\hline Adjusted $R^{2}$ & $4.3 \%$ & $10.1 \%$ & $8.4 \%$ & $35.0 \%$ & $37.9 \%$ & $35.0 \%$
\end{tabular}


Table IA4: Predicting second-period S\&P 500 performance for subperiods

We define our dependent variables as second-period realized return and volatility, measured from the expiry of the nearest maturity options until the expiry of the longer-term options. Realized volatility is computed from high-frequency returns. Independent variables are the index-to-volatility implied correlation (from the Frank copula), VIX, the variance risk premium, and the difference between longand short-term implied skewness. Panel A is based on the first half of the sample (07/2007 to 12/2010), Panel B on the second half (01/2011 to 08/2014). The p-values are based on the Newey and West (1987) standard errors with four lags.

Panel A: first half of the sample (07/2007 to 12/2010)

\begin{tabular}{l|ccc|ccc} 
& \multicolumn{3}{|c|}{ Return } & \multicolumn{3}{c}{ Volatility } \\
\hline & $(1)$ & $(2)$ & $(3)$ & $(4)$ & $(5)$ & $(6)$ \\
Intercept & 0.850 & 0.570 & 0.911 & 0.260 & 0.087 & 0.295 \\
p-val & 0.038 & 0.207 & 0.024 & 0.000 & 0.348 & 0.000 \\
Implied Correlation & 0.973 & 0.901 & 1.021 & 0.038 & -0.012 & 0.057 \\
p-val & 0.046 & 0.046 & 0.031 & 0.755 & 0.271 & 0.938 \\
VIX & - & 0.830 & - & - & 0.471 & - \\
p-val & - & 0.387 & - & - & 0.000 & - \\
Variance Risk Premium & - & - & 0.686 & - & - & -0.528 \\
p-val & - & - & 0.469 & - & - & 0.063 \\
Implied Skewness, long-short & - & -0.061 & -0.149 & - & -0.007 & -0.048 \\
p-val & - & 0.604 & 0.679 & - & 0.517 & 0.054 \\
\hline Adjusted $R^{2}$ & $1.6 \%$ & $2.0 \%$ & $0.8 \%$ & $-0.5 \%$ & $15.2 \%$ & $2.5 \%$
\end{tabular}

Panel B: second half of the sample (01/2011 to 08/2014)

\begin{tabular}{l|ccc|ccc} 
& \multicolumn{3}{|c|}{ Return } & \multicolumn{3}{c}{ Volatility } \\
\hline & $(1)$ & $(2)$ & $(3)$ & $(4)$ & $(5)$ & $(6)$ \\
Intercept & 0.434 & 0.789 & 0.852 & 0.084 & 0.014 & 0.085 \\
p-val & 0.008 & 0.000 & 0.000 & 0.000 & 0.836 & 0.001 \\
Implied Correlation & 0.432 & 0.788 & 0.777 & -0.064 & -0.007 & -0.045 \\
p-val & 0.038 & 0.001 & 0.001 & 0.027 & 0.414 & 0.236 \\
VIX & - & 0.239 & - & - & 0.623 & - \\
p-val & - & 0.679 & - & - & 0.000 & - \\
Variance Risk Premium & - & - & -1.517 & - & - & 1.450 \\
p-val & - & - & 0.958 & - & - & 0.016 \\
Implied Skewness, long-short & - & -0.254 & -0.272 & - & 0.009 & -0.010 \\
p-val & - & 0.004 & 0.001 & - & 0.734 & 0.823 \\
\hline Adjusted $R^{2}$ & $1.5 \%$ & $8.4 \%$ & $8.5 \%$ & $2.4 \%$ & $38.5 \%$ & $12.1 \%$
\end{tabular}


Table IA5: Predicting second period risk-neutral quantities for S\&P 500 for subperiods

We use as dependent variables the selected characteristics of the option-implied distribution of S\&P 500 estimated on the expiry date $t 1$ of the short-term options that are used to calibrate the indexto-volatility implied correlation at time $t$. The dependent variables are the "Right tail minus Left tail" variable computed as the probability mass to the right of the $10 \%$ monthly return minus the probability mass to the left of the $-10 \%$ monthly return (which corresponds approximately to the $\pm 2 \sigma$ event if unconditional market volatility is $17 \%$ p.a.) and implied skewness and volatility that are computed from the estimated risk-neutral density. Independent variables are the index-to-volatility implied correlation, VIX, the variance risk premium, and the difference between long- and short-term implied skewness. Panel A is based on the first half of the sample (07/2007 to 12/2010), Panel B on the second half (01/2011 to 08/2014), and Panel C on the after-crisis period (03/2009 to 08/2014). We use non-overlapping regressions to guarantee that the quantity we want to predict is always observed about one month after the estimation date $t$. For p-values we use White (1980) standard errors adjusted for heteroscedasticity.

Panel A: first half of the sample (07/2007 to 12/2010)

\begin{tabular}{|c|c|c|c|c|c|c|c|c|c|}
\hline & \multicolumn{3}{|c|}{ Right minus Left tail } & \multicolumn{3}{|c|}{ Implied skewness } & \multicolumn{3}{|c|}{ Implied volatility } \\
\hline & (1) & $(2)$ & $(3)$ & (4) & $(5)$ & (6) & $(7)$ & $(8)$ & (9) \\
\hline Intercept & -0.020 & -0.088 & -0.020 & -1.230 & -1.598 & -0.776 & 0.136 & 0.071 & 0.160 \\
\hline p-val & 0.947 & 0.007 & 0.974 & 0.008 & 0.000 & 0.132 & 0.000 & 0.042 & 0.000 \\
\hline Implied Correlation & 0.025 & -0.006 & 0.025 & 0.001 & 0.030 & 0.430 & 0.069 & 0.049 & 0.091 \\
\hline p-val & 0.873 & 0.326 & 0.959 & 0.004 & 0.119 & 0.712 & 0.160 & 0.205 & 0.060 \\
\hline VIX & - & 0.138 & - & - & 1.689 & - & - & 0.181 & - \\
\hline p-val & - & 0.000 & - & - & 0.000 & - & - & 0.000 & - \\
\hline Variance Risk Premium & - & - & 0.002 & - & - & 1.552 & - & - & 0.051 \\
\hline p-val & - & - & 0.026 & - & - & 0.711 & - & - & 0.546 \\
\hline Implied Skewness, long-short & - & 0.024 & 0.001 & - & -0.469 & -0.763 & - & -0.008 & -0.039 \\
\hline p-val & - & 0.331 & 0.060 & - & 0.113 & 0.016 & - & 0.724 & 0.214 \\
\hline Adjusted $R^{2}$ & $-0.9 \%$ & $33.8 \%$ & $-6.1 \%$ & $-2.4 \%$ & $37.8 \%$ & $11.5 \%$ & $5.0 \%$ & $51.8 \%$ & $6.8 \%$ \\
\hline
\end{tabular}

Panel B: second half of the sample (01/2011 to 08/2014)

\begin{tabular}{l|ccc|ccc|ccc} 
& \multicolumn{3}{|c|}{ Right } & minus & Left tail & \multicolumn{3}{|c|}{ Implied skewness } & \multicolumn{3}{c}{ Implied volatility } \\
\hline & $(1)$ & $(2)$ & $(3)$ & $(4)$ & $(5)$ & $(6)$ & $(7)$ & $(8)$ & $(9)$ \\
Intercept & 0.007 & 0.021 & 0.005 & -2.870 & -2.266 & -1.795 & 0.025 & -0.004 & 0.030 \\
p-val & 0.977 & 0.244 & 0.651 & 0.000 & 0.000 & 0.000 & 0.147 & 0.499 & 0.094 \\
Implied Correlation & 0.048 & 0.039 & 0.039 & -1.215 & -0.113 & -0.142 & -0.034 & -0.015 & -0.017 \\
p-val & 0.002 & 0.013 & 0.015 & 0.053 & 0.380 & 0.453 & 0.115 & 0.533 & 0.614 \\
VIX & - & -0.121 & - & - & 3.162 & - & - & 0.245 & - \\
p-val & - & 0.004 & - & - & 0.032 & - & - & 0.000 & - \\
Variance Risk Premium & - & - & -0.502 & - & - & 9.383 & - & - & 0.912 \\
p-val & - & - & 0.021 & - & - & 0.317 & - & - & 0.000 \\
Implied Skewness, long-short & - & -0.001 & 0.005 & - & -0.829 & -0.999 & - & 0.001 & -0.011 \\
p-val & - & 0.232 & 0.918 & - & 0.002 & 0.000 & - & 0.341 & 0.328 \\
\hline Adjusted $R^{2}$ & $21.2 \%$ & $36.4 \%$ & $31.4 \%$ & $8.8 \%$ & $44.4 \%$ & $38.8 \%$ & $6.0 \%$ & $55.8 \%$ & $34.6 \%$
\end{tabular}

Panel C: after-crisis period (03/2009 to 08/2014)

\begin{tabular}{l|ccc|ccc|ccc} 
& \multicolumn{3}{|c|}{ Right } & minus & Left tail & \multicolumn{3}{|c|}{ Implied skewness } & \multicolumn{3}{c}{ Implied volatility } \\
\hline & $(1)$ & $(2)$ & $(3)$ & $(4)$ & $(5)$ & $(6)$ & $(7)$ & $(8)$ & $(9)$ \\
Intercept & 0.002 & 0.008 & -0.002 & -2.792 & -2.338 & -1.671 & 0.037 & 0.017 & 0.055 \\
p-val & 0.348 & 0.947 & 0.210 & 0.000 & 0.000 & 0.000 & 0.007 & 0.275 & 0.000 \\
Implied Correlation & 0.044 & 0.037 & 0.037 & -1.294 & -0.072 & -0.134 & -0.024 & 0.006 & 0.003 \\
p-val & 0.000 & 0.010 & 0.012 & 0.006 & 0.314 & 0.509 & 0.230 & 0.752 & 0.311 \\
VIX & - & -0.056 & - & - & 3.729 & - & - & 0.217 & - \\
p-val & - & 0.082 & - & - & 0.000 & - & - & 0.000 & - \\
Variance Risk Premium & - & - & -0.213 & - & - & 9.395 & - & - & 0.635 \\
p-val & - & - & 0.249 & - & - & 0.065 & - & - & 0.000 \\
Implied Skewness, long-short & - & -0.001 & 0.004 & - & -0.707 & -1.025 & - & 0.000 & -0.018 \\
p-val & - & 0.177 & 0.880 & - & 0.001 & 0.000 & - & 0.074 & 0.049 \\
\hline Adjusted $R^{2}$ & $17.9 \%$ & $21.3 \%$ & $19.0 \%$ & $11.3 \%$ & $52.0 \%$ & $38.3 \%$ & $2.3 \%$ & $59.6 \%$ & $24.7 \%$
\end{tabular}


Figure IA1: Index-to-vol correlation with different copula functions

The figure shows the time series of the Implied Index-to-vol Correlation over the sample period from July 2007 until August 2014 for three different copula functions used to model the dependency between the market return and its future expected volatility: Frank, Student's t, and Gaussian copulas.

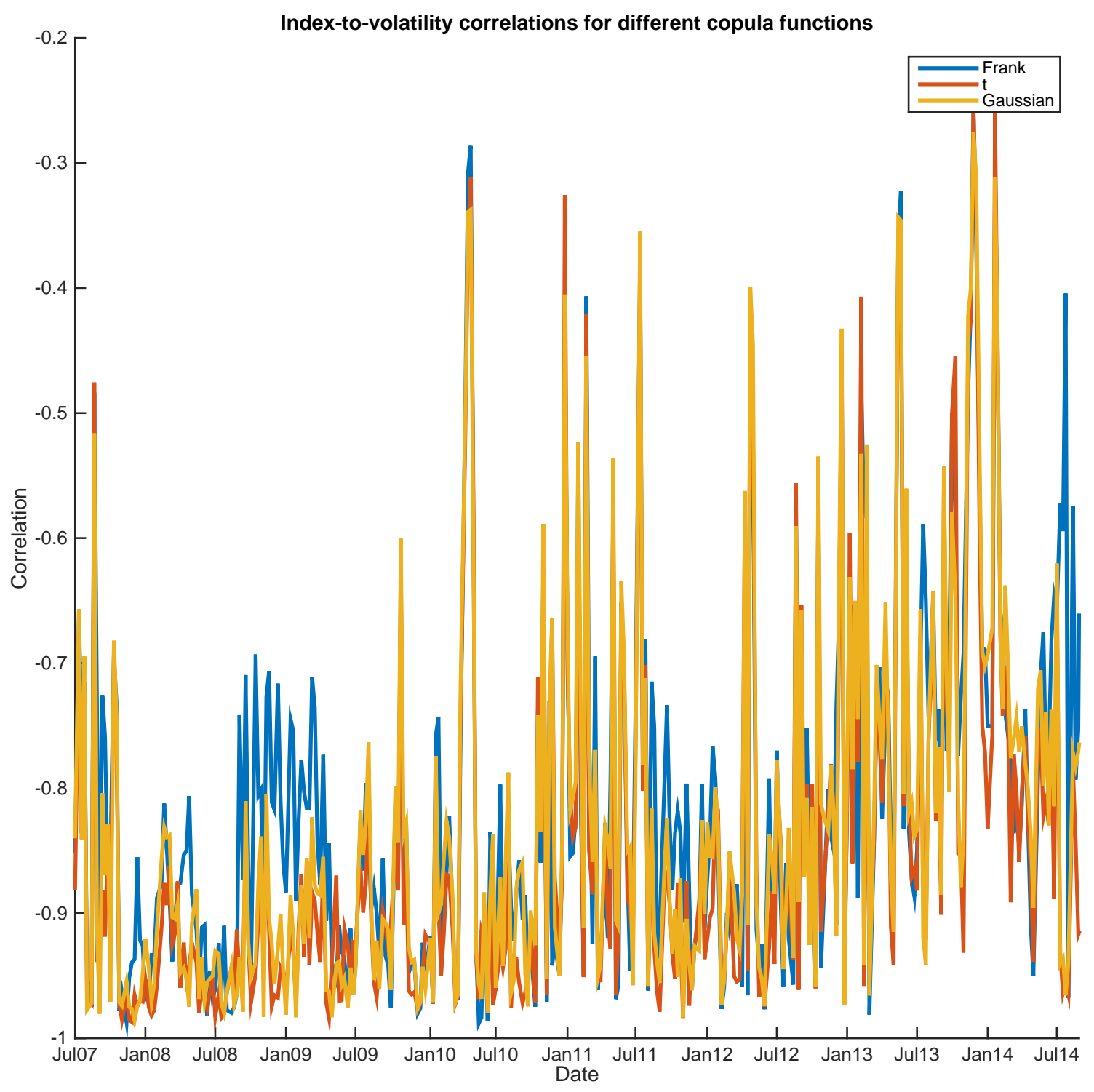

